\title{
E1 sistema histórico de riego de la Vega de Granada. Reconocimiento y protección desde la perspectiva del Patrimonio Agrario.
}

\author{
José Castillo Ruiz, Celia Martínez Hidalgo y Gloria Pérez Córdoba \\ Universidad de Granada \\ jcastill@ugr.es,celiamarmar@gmail.com,gloriaperez@ugr.es
}

\begin{abstract}
Resumen. Los sistemas históricos o tradicionales de riego constituyen un tipo de espacio agrario de grandes valores culturales y naturales, los cuales requieren un adecuado reconocimiento y protección. Para proceder a esta valoración patrimonial consideremos que el enfoque adecuado debe ser el derivado del concepto de Patrimonio Agrario, ya que, con independencia de los valores propiamente hidráulicos que disponen estos sistemas, su razón de ser es la irrigación de un territorio para su explotación agraria y, a partir de ahí, la construcción de un asentamiento humano. Tomando como referencia los presupuestos que caracterizan el Patrimonio Agrario, elaborados en el contexto del Proyecto PAGO (El Patrimonio Agrario. La construcción cultural del territorio a través de la actividad agraria, HAR2010-15809), en este texto establecemos cuáles son los valores que deben reconocerse en los sistemas históricos de riego y, sobre todo, los criterios y mecanismos a utilizar para su delimitación y protección. Para avalar todas estas propuestas utilizamos como ejemplo el caso de la Vega de Granada, cuyo extraordinario sistema hidráulico está siendo objeto de un estudio en profundidad por parte del Proyecto PAGO.
\end{abstract}

Palabras clave. Patrimonio Agrario. Regadíos Históricos. Protección. Vega de Granada. Patrimonio Cultural.

\begin{abstract}
Traditional irrigation systems preserve important natural and cultural values, which deserve protection and reconnaissance. In order to develop this heritage assessment the focus should be placed on the concept of Agrarian Heritage, because despite the important hydraulic values of these systems, irrigation is a mere instrument for agrarian production and human settlements. This paper, based on the Project PAGO (Agrarian Heritage: cultural landscape construction through agrarian activity, HAR2010 15809), stablishes which are the values that should be considered in the historical irrigation systems, and mainly, the mechanisms and criteria for delimitation and protection, focusing in the study case of the Vega the Granada hydraulic system.
\end{abstract}

Keywords. Agrarian Heritage. Historical Irrigation. Protection. Vega of Granada. Cultural Heritage

\section{Introducción. La relevancia patrimonial de los regadíos históricos}

Los regadíos históricos constituyen un tipo de espacio agrario o construcción cultural de gran relevancia patrimonial, ya que confluyen en ellos muchos de los valores y dimensiones emergentes en la actual caracterización y protección del Patrimonio Cultural: interrelación de bienes culturales y naturales, territorio, paisaje, bienes intangibles, dimensión productiva, etc.

Si bien estos sistemas hidráulicos y espacios agrarios generados por ellos han suscitado la atención de numerosas disciplinas, especialmente la Geografía, propiciando todo tipo de estudios sobre ellos, no ha sido hasta los últimos años cuando han empezado a considerarse desde la perspectiva patrimonial, con lo que ello implica, por un lado, de identificación y caracterización de sus valores culturales y naturales y, por otro lado, de 
proposición y aplicación de instrumentos y mecanismos de ordenación, gestión y protección de dichos espacios ${ }^{1}$.

Tomando como referencia estos estudios y propuestas hasta ahora realizados, nuestra intención es situar la valoración de los regadíos históricos en el contexto del nuevo concepto de Patrimonio Agrario que es, desde nuestro punto de vista, el marco conceptual desde el que habría que hacer el reconocimiento y actuación patrimoniales de éste y de cualquier otro bien relacionado con la actividad agraria. Esto significa que partimos de dos presupuestos a la hora de abordar nuestro análisis:

- El primero, que valoramos los sistemas de riego históricos en virtud de la que consideramos que es su función fundamental, la agraria; función ésta que en la mayoría de los casos está en el origen y continuidad en el tiempo de dichos sistemas. Esto no significa que no se consideren todas aquellas otras funciones vinculadas a estos sistemas: abastecimiento de agua, lavaderos, molinos, generación de energía hidroeléctrica, navegación, transporte, etc. Pero lo hacemos reconociendo (con las excepciones oportunas) su condición de funciones derivadas, subordinadas o complementarias.

- El segundo, que nuestro objetivo es definir patrimonialmente estos sistemas, lo que exige que se incluyan en este análisis todas aquellas dimensiones y exigencias metodológicas que reclama la tutela del Patrimonio Histórico: identificación de valores, criterios de delimitación, mecanismos de protección, etc.

Esta nueva orientación que aquí proponemos surge a raíz de la investigación desarrollada por el Proyecto Pago (El Patrimonio Agrario. La construcción cultural del territorio a través de la actividad agraria. Ministerio de Economía y Competitividad. HAR2010-15809)2 , del cual formamos parte los autores de esta comunicación, cuyo principal objetivo es definir y caracterizar el Patrimonio Agrario, al que reclamamos como un nuevo tipo de bien cultural, así como el de establecer los criterios y mecanismos que deben regir su protección, gestión y dinamización.

Aunque los regadíos históricos en España no son uniformes, ya que se han ido conformando a lo largo de las diferentes etapas históricas de nuestro país (Hermosilla, 2010:11-20), existen en ellos unas claves valorativas muy semejantes (derivadas de su naturaleza material y funcional) que nos permiten extraer principios y criterios para su caracterización patrimonial comunes para todos. No obstante, quisiéramos señalar que las conclusiones que presentamos en este trabajo derivan fundamentalmente de los regadíos pertenecientes a una etapa histórica determinada (la medieval islámica) y en particular de los existentes en la Vega de Granada, que es el espacio agrario que hemos elegido en el Proyecto PAGO para aplicar sobre la realidad nuestra metodología de valoración patrimonial del Patrimonio Agrario.

Desde la perspectiva del Proyecto PAGO, los sistemas históricos de riego debemos considerarlos como un tipo de bien más de los integrantes del Patrimonio Agrario. Esto significa que la caracterización, valoración, ordenación, protección y gestión de los mismos

${ }^{1}$ Quisiera destacar al respecto la obra colectiva Regadíos Históricos españoles, dirigida por Jorge Hermosilla y financiada por el Ministerio de Medio Ambiente y Medio Rural y Marino en 2010, en la cual, al margen de la descripción de los diferentes regadíos existentes en la geografía española, avanzan una primera valoración patrimonial en función de una metodología concreta definida en este trabajo.

${ }^{2}$ http://www.patrimonioagrario.es/pago/PRESENTACION_.html. 
deben supeditarse a las exigencias que marca el Patrimonio Agrario. Veamos primero las claves que sustentan el Patrimonio Agrario y luego su efecto sobre los sistemas históricos de riego.

\section{Claves del Patrimonio Agrario}

La evolución experimentada por el concepto de Patrimonio Cultural en los últimos años ha permitido que nuevos tipos de bienes (el Patrimonio Industrial, el Patrimonio del Movimiento Moderno o el Patrimonio Audiovisual, ) hayan adquirido un reconocimiento y tratamiento diferenciado (Martínez Yáñez, 2011). Esto ha permitido mejorar sustancialmente su caracterización y protección. El objetivo de nuestro proyecto es conseguir que también el Patrimonio Agrario consiga este tratamiento diferenciado. Esto significaría incluir el valor agrario (al igual que ha sucedido con otros valores como el industrial, paisajístico, tecnológico, etc.) como uno de los valores a proteger por la legislación de Patrimonio Cultural y, derivado de ello, al Patrimonio Agrario como un nuevo tipo de bien cultural, tal y como sucede, por ejemplo, con el Patrimonio Industrial.

Las claves principales de este nuevo Patrimonio, recogidas en un documento elaborado por el Proyecto PAGO, la Carta de Baeza del Patrimonio Agrario (Castillo Ruiz, 2013³), son las siguientes:

- El elemento fundamental del Patrimonio Agrario, el que constituye su esencia patrimonial, es la actividad agraria. Por lo tanto, todos los aspectos que deben conformar su tutela (definición, tipos de bienes que lo integran, categorías y figuras legales de protección, mecanismos de gestión y difusión) tienen que derivar de este principio fundamental: el mantenimiento de la actividad agraria como garantía para la preservación y continuidad futura de los bienes objeto de protección. Se trata por tanto de un patrimonio vivo.

- El Patrimonio Agrario "está conformado por el conjunto de bienes naturales y culturales, materiales e inmateriales, generados o aprovechados por la actividad agraria a lo largo de la historia" (Castillo Ruiz, 2013:32).

- El reconocimiento patrimonial del Patrimonio Agrario implica que el principal valor que debe sustentar su consideración y salvaguarda es el cultural, lo que supone entender la actividad agraria como una práctica social de indudable y crucial aportación a la civilización humana. No obstante, este valor cultural debe entenderse desde una dimensión histórica y/o tradicional, ya que la actividad agraria a preservar es aquella que, fundada en prácticas tradicionales de manejo sustentables, se ve amenazada en la actualidad, entre otras causas, por la agricultura productivista e industrializada.

- Además de este genérico valor cultural, el Patrimonio Agrario debe asumir como propios aquellos valores y significados más elevados y trascendentes que la agricultura, la ganadería y la silvicultura representan y han representado para toda la humanidad. Son los siguientes:

- Su crucial e insustituible aportación a la alimentación de las personas, tanto en su condición de elemento fundamental para la supervivencia -lo que lo convierte en un derecho humano fundamental- $y$, en su caso, para la

\footnotetext{
3 La versión electrónica de este documento se puede consultar en http://www.patrimonioagrario.es/pago/CARTA_DE_BAEZA_files/carta.pdf
} 
soberanía alimentaria, como por su relación con la consecución de una vida sana y saludable, además de justa y solidaria.

- Su relación armónica con el territorio, manifestada en un aprovechamiento sostenible y dinámico de los recursos naturales, en una adecuación respetuosa a las condiciones naturales del medio físico y, finalmente, en la mínima afección a las condiciones medioambientales de dicho territorio.

- Su imprescindible contribución a la diversidad biológica (manifestada en la heterogeneidad genética de las variedades locales y razas autóctonas) y cultural (la asociada a las innumerables formas de manejo existentes en el mundo).

- La actividad agraria no puede reconocerse y mantenerse en un solo bien, ni siquiera en un conjunto de ellos, sino que se manifiesta y se desarrolla en un ámbito territorial. Por esta razón, el procedimiento para identificar y preservar el Patrimonio Agrario debe ser de carácter territorial.

\section{Valoración de los sistemas históricos de riego desde la perspectiva del Patrimonio Agrario. El caso de la Vega de Granada.}

Hay tres cuestiones que debemos dilucidar en relación a la valoración patrimonial de los sistemas hidráulicos históricos desde esta perspectiva del Patrimonio Agrario:

- La identificación de los valores patrimoniales que disponen y, a partir de ellos, los criterios que deben seguirse para determinar la mayor o menor relevancia del sistema de riego a proteger.

- El establecimiento de los criterios para su delimitación como un espacio patrimonial formalmente constituido.

- La determinación de los mecanismos de protección de los mismos.

Vamos a proceder a analizar estas tres cuestiones tomando como referencia o ámbito de aplicación el caso de la Vega de Granada.

\subsection{Valores patrimoniales de los sistemas de regadío histórico}

La perspectiva integral y holística consustancial al concepto de Patrimonio Agrario implica que en la valoración patrimonial de los sistemas históricos de riego debamos considerar todas las dimensiones y valores que concurren en ellos. Son los siguientes:

\section{a) Valores culturales materiales.}

Incluiría los valores históricos, técnicos y artísticos relacionados con el sistema hidráulico propiamente dicho (acequias, azudes, presas, partidores, norias, etc.) así como con los elementos constructivos vinculados a dicho sistema (molinos, albercas, abrevaderos, lavaderos, etc.).

En el caso de la Vega de Granada, los valores culturales materiales son extraordinarios aunque referidos fundamentalmente al sistema hidráulico en general, a la conformación de un sistema interrelacionado de acequias de miles de kilómetros que aunque procedentes de diferentes puntos de captación del agua (las que aprovechan las aguas superficiales, especialmente del río Genil y sus afluentes -Darro, Beiro, Monachil, Dílar, Cubillas y 
Velillos-, las que utilizan los afloramientos del poderoso acuífero de la Vega, ubicadas especialmente en la zona Oeste, y las que se configuran en la zona Norte a partir de los manantiales de naturaleza cárstica de la Sierra de Huétor) conforman un espacio histórico de riego de una indiscutible unidad geográfica y, sobre todo, funcional y productiva, hecho éste reforzado por el incuestionable reconocimiento social de la Vega de Granada como un territorio único y dotado de una fuerte identidad.

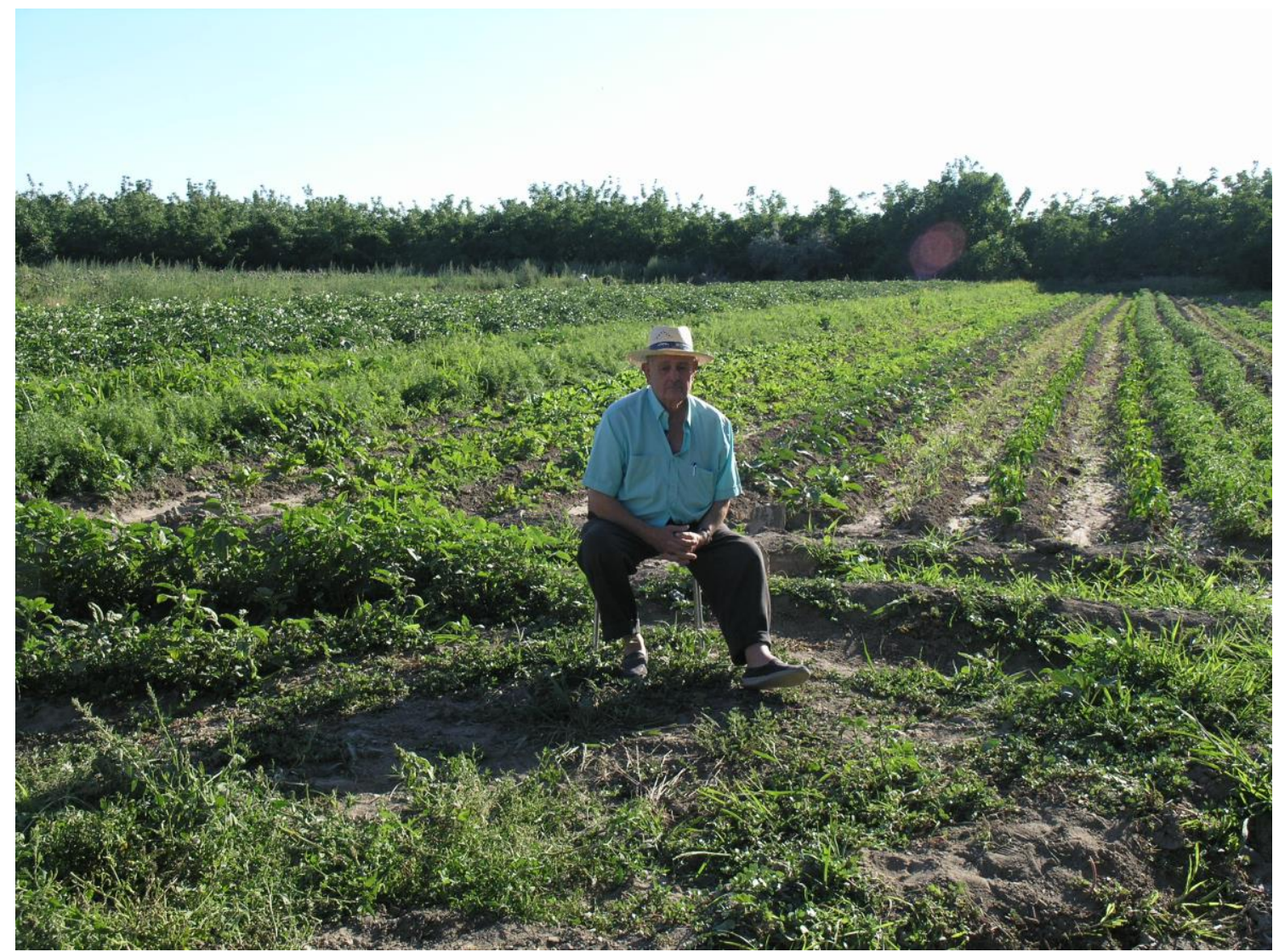

Fig. 1. Antonio Hurtado, "el Niñillo". Tesoro vivo de la Vega de Granada. CJosé Castillo Ruiz.

Por lo que respecta a los elementos materiales considerados singularmente apenas si existen bienes de relevancia histórico-artística o técnica ${ }^{4}$ en la Vega de Granada, ya que, por un lado, el escaso desnivel del espacio irrigado hace innecesario la construcción de estructuras permanentes para la conducción del agua (como acueductos, puentes, etc.) y, por otro lado, la captación del agua en los ríos a través de presas adaptables al caudal y, por tanto, realizadas con materiales provisionales y de acarreo (piedras, maderas, ramas, etc.), hace que no encontremos estructuras hidráulicas permanentes de importancia.Si a esto unimos que las construcciones vinculadas a las acequias como molinos, fuentes, abrevaderos, etc. han desaparecido en su mayoría, podemos concluir que la riqueza patrimonial referida a los elementos hidráulicos materiales es limitada y reducida. Está es quizás además una de las razones que está impidiendo que haya un mayor reconocimiento social o institucional del valor cultural de la Vega de Granada, ya que la extendida concepción monumentalista del

\footnotetext{
4 .Una excepción sería la Acequia de Aynadamar, donde los importantes restos materiales (cauce, puentes, túneles, etc.) del trazado originario conservados le han hecho merecedora de su declaración singular como BIC, Zona Arqueológica, en una parte de su trazado.
} 
Patrimonio Cultural hace que no se sepa apreciar el extraordinario valor histórico, agrícola y técnico del impresionante sistema hidráulico existente en ella. No obstante, en el conjunto de la Vega de Granada encontramos obviamente elementos hidráulicos relevantes que conviene resaltar como presas y azudes(el azud sobre el río Cubillas, las denominadas "Medias lunas" de Pinos Puente como la de Búcor sobre el río Velillos o el azud del Blanqueo sobre el río Genil); puentes y acueductos (el acueducto del Arco de la acequia de Otura, los diferentes túneles, puentes y acueductos de la Acequia del Fardes, el acueducto sobre el arroyo de Chimeneas o el puente sobre el antiguo cauce del río Dílar) partidores y acequias (el partidorde "la Teja" de la Huerta del Sagrado Corazónen la acequia Gorda, el partidor de la acequia de la Estrella en HuétorVegao los partidores de la acequia del Barranco de la Era Alhendín); molinos (la Huerta-Molino Corazón de Jesús en la acequia Gorda, el Molino de Florencio en acequia de Aynadamar, el molino del Martinete en Fuente Vaqueros o el Molino de la Aurora o Zambrano en la Acequia de Otura; fuentes(Fuente Grande y Fuente Chica en Alfacar), etc.

Mención especial merece dentro de los valores culturales materiales el valor territorial. Este valor se refiere a la capacidad que tienen los sistemas de riego para expresar la forma, mecanismos y principios que tienen una determinada cultura para aprovechar y explotar los recursos naturales e integrarse en el medio, tal y como sucede, por ejemplo, con la cultura de Al-Andalus (Martín Civantos, 2011:12). Esto significa que uno de los principales valores que adquieren los sistemas de riego históricos es su trazado, cuya preservación o continuidad es la clave de su condición patrimonial. Por lo general, el trazado de un sistema de riego dispone de un altísimo grado de autenticidad, ya que su dependencia de los recursos naturales, la orografía del terreno y de los medios productivos de la época en los que se construyó les dota de un carácter de permanencia y estabilidad superior a cualquier otro tipo de bien inmueble. Esto es lo que sucede, por ejemplo, con los riegos históricos musulmanes en España, en particular con los de la Vega de Granada (Ocaña Ocaña, 1974; Malpica Cuello, 1998; Ruiz Ruiz, 2013).

Efectivamente, el sistema hidráulico de la Vega de Granada dispone de un alto grado de autenticidad, el cual se manifiesta en la continuidad histórica del trazadodel sistema de riego diseñado y construido en época medieval islámica que, con independencia de los antecedentes romanos existentes (que se pueden identificar a través de restos de dos presas en el río Cubillas y en el posible mantenimiento de la estructura parcelaria regular en torno a la ciudad romana de Illurco, la actual Pinos Puente), es cuando debemos situar su origen. Aunque la noticia documental más antigua que disponemos del riego en la Vega es el repartimiento de las aguas del Genil de 1219 (Repartimiento de AbdAllah), en época almohade, el trazado de sus elementos más importantes estaba ya configurado desde la época emiral o califal, alcanzando pleno desarrollo en época zirí y nazarí. (Castillo Ruiz y Cejudo García, 2012: 268) Esto significa, y queremos resaltarlo especialmente, que la Vega de Granada existía con anterioridad a la propia fundación de la ciudad de Granada, cuyo origen debemos situar en el traslado que en el siglo XI se produce de la capitalidad de la Cora Elvira desde su ubicación originaria en la ciudad de Ilbira (situada a los pies de Sierra Elvira en el término actual de Atarfe) hasta la de Garnata, lo cual se hace, como indica Antonio Malpica, sobre un espacio, el que integraba la Vega, denominada al-Fahs, que estaba bien poblado, con una agricultura a plena producción gracias a la amplia red de acequias que, en cierta manera, la ciudad de Granada vino incluso a alterar: "Es evidente, así mismo, que Granada se inserta en un espacio ya desarrollado, al que distorsiona en buena medida..." (Malpica Cuello, 1998, 231). 

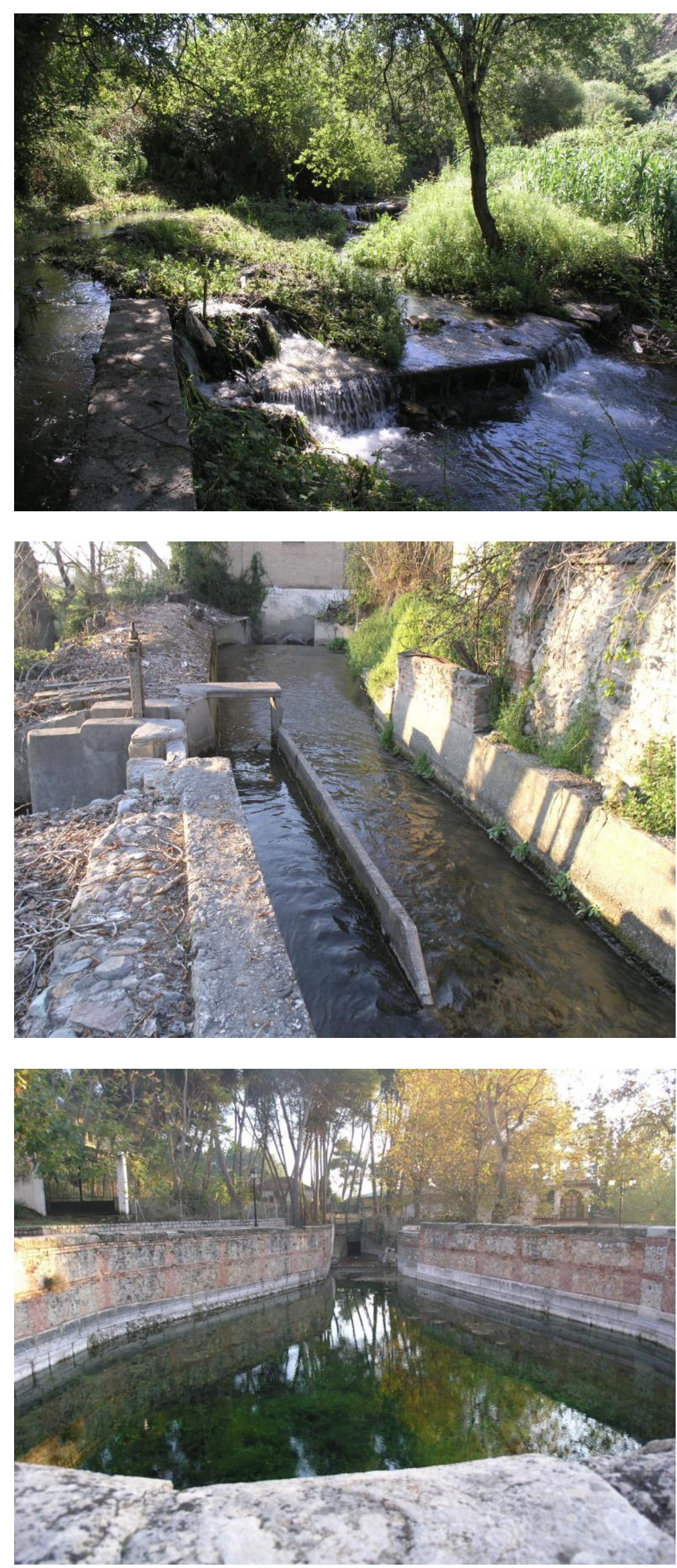

Fig. 2. Presa de la que capta el agua del río Monachil la acequia de la Estrella. CJosé Castillo Ruiz.

Fig. 3. Toma de agua de la Teja de la Huerta del Sagrado Corazón (Pago de Jaragüit Bajo, Acequia Gorda, Granada). (CJosé Castillo Ruiz

Fig. 4. Fuente Grande.

Nacimiento de la Acequia de Aynadamar (Alfacar, Granada). C) José Castillo Ruiz. 
El sistema hidráulico creado por la cultura islámica, como estableció Carmen Ocaña y luego ha sido reiterado de forma unánime por la historiografía posterior, se va a mantener prácticamente inalterado hasta la mitad del siglo XX: "El mantenimiento de las acequias y la construcción nueva de algunas presas, no llega a producir ninguna desvirtuación esencial, de modo que en 1950, los limites de la vega granadina no diferían prácticamente de la vega musulmana”. (Ocaña Ocaña, M.C., 1971, 63). Hasta ese momento el único cambio significativo respecto a la situación islámica será el proceso de desecación y roturación del sitio real del Soto de Roma, una zona boscosa y pantanosa situada en torno a la actual localidad de Fuente Vaqueros ${ }^{5}$. Será a partir de la década de los 50del siglo XX cuando entren en funcionamiento, primero con la construcción del Canal de Albolotea finales de la década de los 40 y luego con el Canal del Cacín, cuando realmente se produzca una extensión significativa de los límites históricos de la Vega, ampliándose en casi un 50\% los límites tradicionales de la misma.

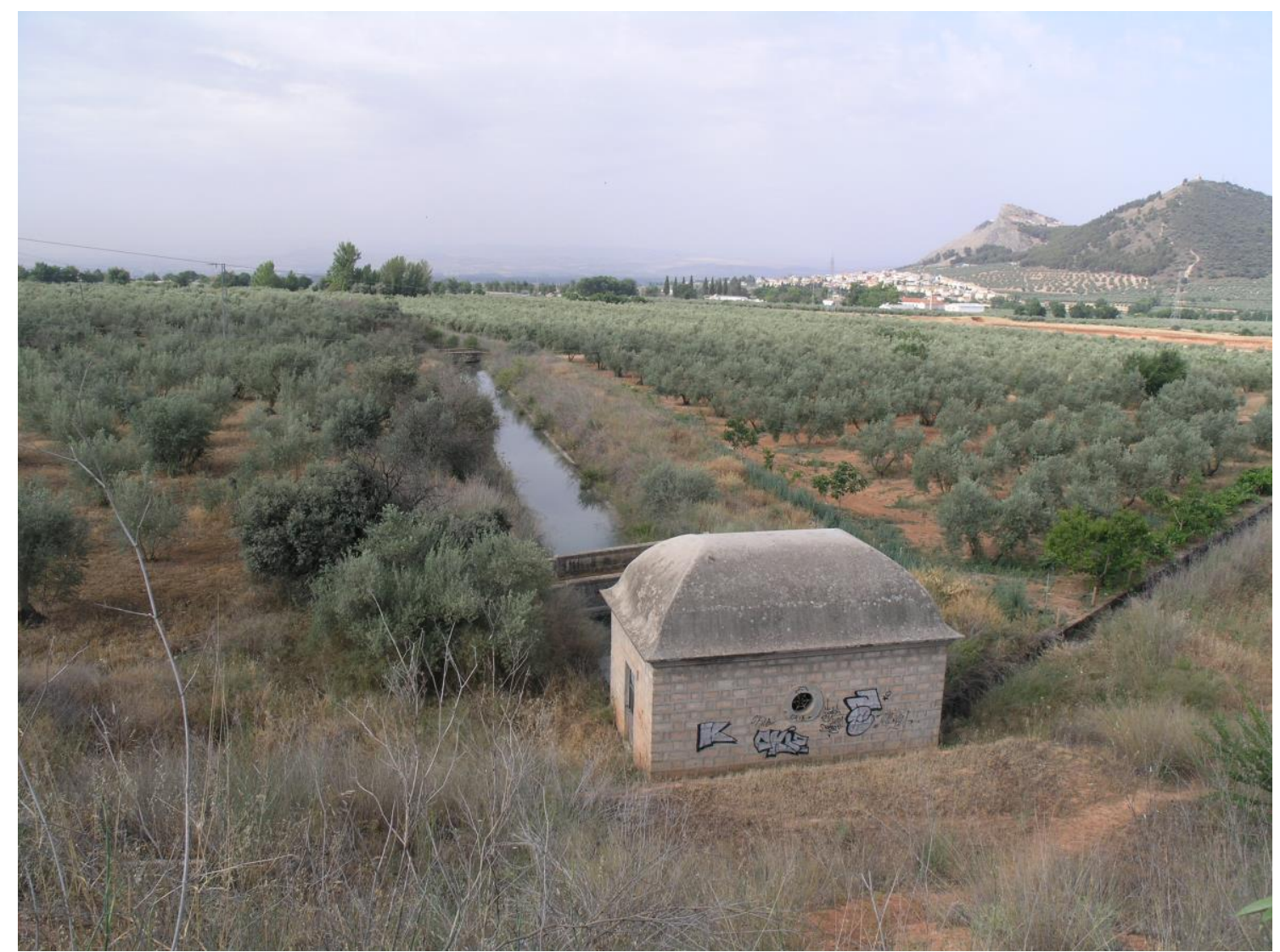

Fig. 5. Partidor del Canal de Albolote. CJosé Castillo Ruiz.

Como ejemplo de esta relevancia patrimonial del trazado del sistema hidráulico de la Vega de Granada quisiéramos comentar el caso de la Acequia del Fardes, una de las unidades de riego que ha sufrido más alteraciones de su espacio irrigado y cultivado en los últimos años, aunque sin embargo ha conseguido mantener, con algunas variaciones no fundamentales, su audaz y complejo trazado histórico.

\footnotetext{
5 Propiedad de la familia real nazarí, pasará a manos de los Reyes Católicos, manteniéndose dentro del Patrimonio Real hasta la segunda mitad del siglo XVIII, cuando la propiedad es cedida sucesivamente a ilustres servidores de la Corona, el último, y en este caso por decisión de las Cortes de Cádiz en 1813, al Duque de Wellington, quien mantiene la propiedad hasta la mitad del siglo XX, cuando, tras varios intentos de expropiación reclamados por los colonos, fue vendida prácticamente en su totalidad a éstos a partir de 1940 (Ver Cuevas Pérez, José. 2006).
} 
El Canal de Fardes ${ }^{6}$ es una obra de ingeniería hidráulica de 22 kilómetros de recorrido que nace en Prado Negro, en el Parque Natural de Huétor Santillán, en el margen izquierda del arroyo Fardes y muere en el Puente de los Ocho Ojos, punto crucial donde se distribuye el agua del Canal para los municipios de Jun, Pulianas y Pulianillas recorriendo parajes como la Cueva del Sol o el Cortijo de Carialfaquí. A lo largo de su traza, aparecerán acueductos, túneles, sifones, etc. que modelarán la topografía hasta llegar a la zona regable, descendiendo desde los $1440 \mathrm{~m}$ a los $750 \mathrm{~m}$, donde abandona la dirección de escorrentía de la topografía para seguir las curvas de nivel. Con tramos canalizados, en mina y embovedados, con tramos excavados por las faldas de la Sierra de Arana y paraje de las Buitreras y con varias presas de cantería como la Presa del Río Bermejo, hacen de esta acequia una de las más relevantes de la existentes en la Vega de Granada.

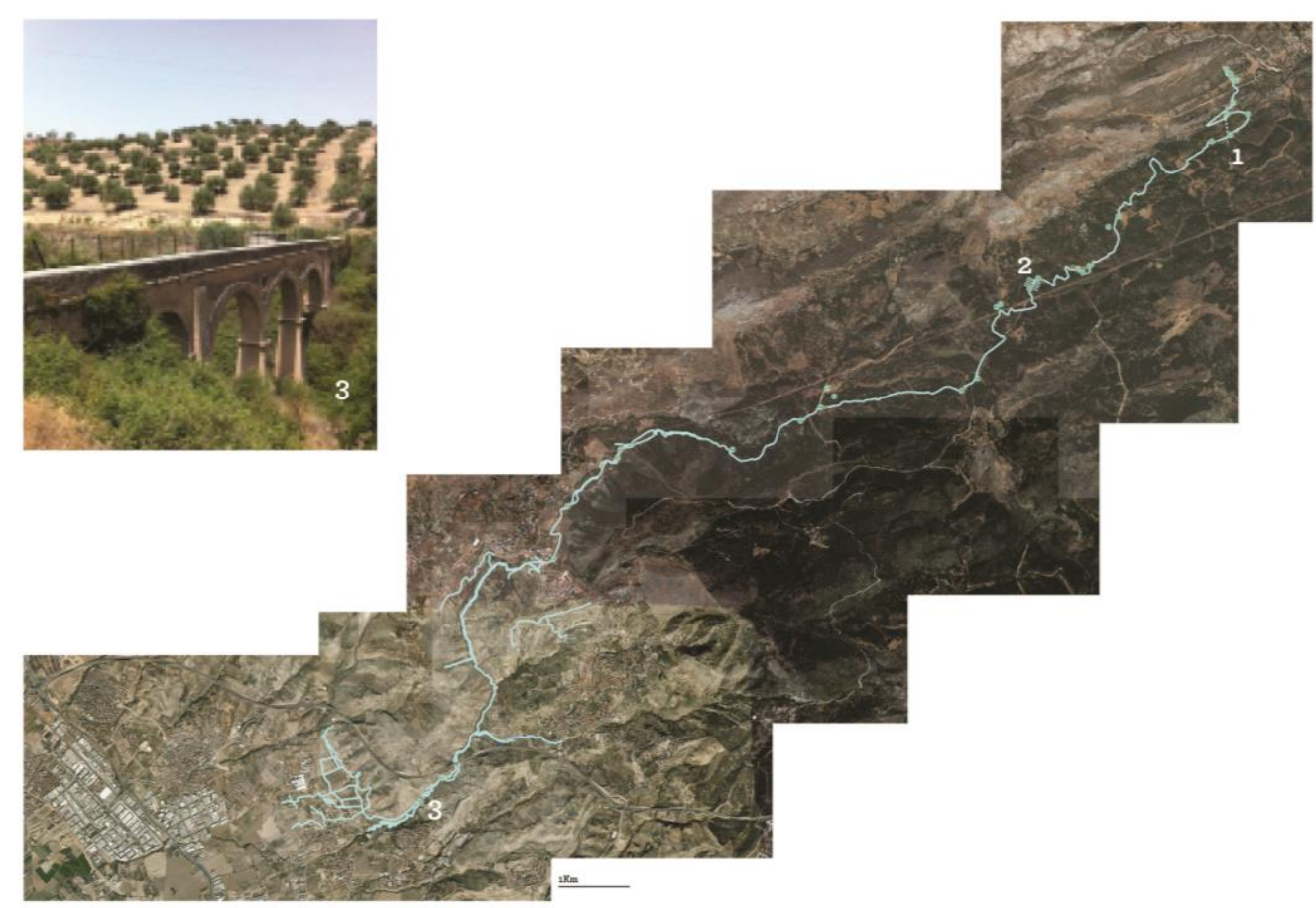

Trazado del Canal de Fardes, desde su nacimiento en la Sierra de Huetor a la vega de Pulianas.

1. Modificación de trazado: acortamiento, tramo soterrado y embovedado

2. Modificación de trazado: tramo soterrado y embovedado

3. Acueducto

Fig. 6. Trazado Canal del Fardes. CCelia Martínez Hidalgo y Gloria Pérez Córdoba.

b) Valores culturales inmateriales.

Se refiere a los valores históricos, técnicos y agrarios relacionados especialmente con el sistema de captación y distribución del agua, así como con los saberes relacionados con el cultivo de la tierra a partir del uso y conducción del agua por las parcelas en las que se cultiva (Mata Olmo y Fernández Muñoz, 2010). Aquí deberíamos incluir el carácter comunal o colectivos de los derechos de agua, los cuales deberían considerarse también como patrimonio cultural (Ostrom, 1990).

${ }^{6}$ Para más información consultar Martínez Hidalgo y Pérez Córdoba, 2013. 
Es aquí, en esta dimensión inmaterial, donde el históricosistema hidráulico de la Vega de Granada manifiesta todo su esplendor y valor patrimonial, ya que sigue manteniendo en un altísimo grado el sistema de riego medieval originario, sobre todo, al continuar con su principal actividad, la agrícola. Aunque el sistema hidráulico originario tenía diferentes funciones (abastecimiento de agua para la población, fuerza motriz de molinos, etc.), la principal era la del riego para la agricultura, función ésta que sigue siendo la predominanteen la actualidad. Que se mantenga el uso originario ya es en sí excepcional, pero además hacerlo conservando en gran medida el sistema de organización y gestión del agua lo convierte en extraordinario. Esta pervivencia podemos apreciarla en la propiedad colectiva del agua, en la organización autónoma de cada acequia (originariamente por el clan familiar de la alquería y desde finales del siglo XIX por las comunidades de regantes), aunque de forma interrelacionada con el resto de comunidades (especialmente las pertenecientes al mismo río), en la distribución del agua por pagos, en la utilización de turnos y tandas (aunque ya reducidos a épocas de enorme escasez de agua) o, muy especialmente, en la forma de riego de los cultivos.En este sentido señalar que de forma casi exclusiva, el riego utilizado en la Vega es el tradicional, es decir, el riego a manta, lo que sitúa al agricultor como el último eslabón (o el destinatario final) de todo el sistema hidráulico: el agua que viene por la acequia, al levantar la compuerta entra en la parcela, primero recorre un surco luego otro y otro.... hasta ir inundando toda la superficie. El agua cubre la tierra, queda retenida, quieta, permitiendo su lenta percolación al subsuelo, alimentando las plantas y llegando al acuífero. El proceso, sencillo, dista de ser simple, pues no es fácil que el agua quede repartida por igual en toda la parcela, evitando el encharcamiento o agostamiento de las plantas; ese trabajo lo realiza el agricultor, repartiendo el agua, abriendo canales sobre la tierra, cortando el paso de agua cuando es suficiente. En definitiva, el agricultor no sólo riega su parcela o cultiva lo sembrado, sino que mantiene y perpetúa unos conocimientos y técnicas de trabajo profundamente arraigadas en el tiempo y en la cultura.

Queremos destacar a modo de ejemplo la distribución del agua que realizan las diferentes acequias que captan el agua del río Monachil y que riegan la denominada Vega Sur ${ }^{7}$. Para ello reproducimos la precisa descripción realizada por Carmen Ocaña, corroborada por los testimonios orales aportados por el antiguo acequiero de la acequia deljacín, Antonio Hurtado, "el Niñillo": "La distribución de las aguas del Monachil entre las acequias se hace de forma tan tradicional, que se ajusta con toda exactitud a la establecida en el Apeo de Loaisa. Según ella, el caudal del río se divide en once partes, de las cuales cuatro y media le corresponde a la acequia Gorda de la Zubia (riega en 535 Has), una parte a la Genital (137/12has), otra parte a la de Albaricoque (221/12 has), y otras cuatro y media a la Estrella y sus derivadas. Para llevar a cabo esta distribución, el cauce del río es interceptado por una presa, en el término de Monachil, conduciendo todas las aguas por una misma acequia basta el partidor del Molino de la Jaca dentro del mismo término; en él, el caudal se divide por mitad entre las dos orillas del río, de forma que cinco onceavas partes y media pasan a la orilla derecha y otras tantas a la izquierda. Por la orilla derecha la toman las acequias Albaricoque y Estrella, y por la izquierda, la Gorda y la Genital” (Ocaña.1971:67)

Dentro de esta dimensión inmaterial de los sistemas históricos de riego quisiera destacar especialmente el de la unidad espacial regada en un mismo turno a partir de la cual se organiza la secuencia de riego en un sistema hidráulico determinado. En el caso de la Vega de Granada estas unidades se denominan pagos, aunque también reciben el nombre de

\footnotetext{
7 Aguas arriba existen otras acequias que también captan el agua del río Monachil, aunque funcionan de forma independiente a las que riegan la Vega Sur por lo que no pertenecen al ámbito espacial-patrimonial de la Vega de Granada.
} 
dulas o trances.Estas unidades de riego son mucho más que espacios para distribuir el agua de forma ordenada, confluyen en ellas todo un sistema complejísimo de construcción física del territorio, estructuración y organización funcional y jurídica del mismo (referido a la titularidad de la tierra y del agua) (Trillo, 2004), el cual es el resultado además de un proceso diacrónico en el que se han ido superponiendo diferentes culturas que lejos de alterar lo conformado en época islámica lo han enriquecido con sus diferentes aportaciones.

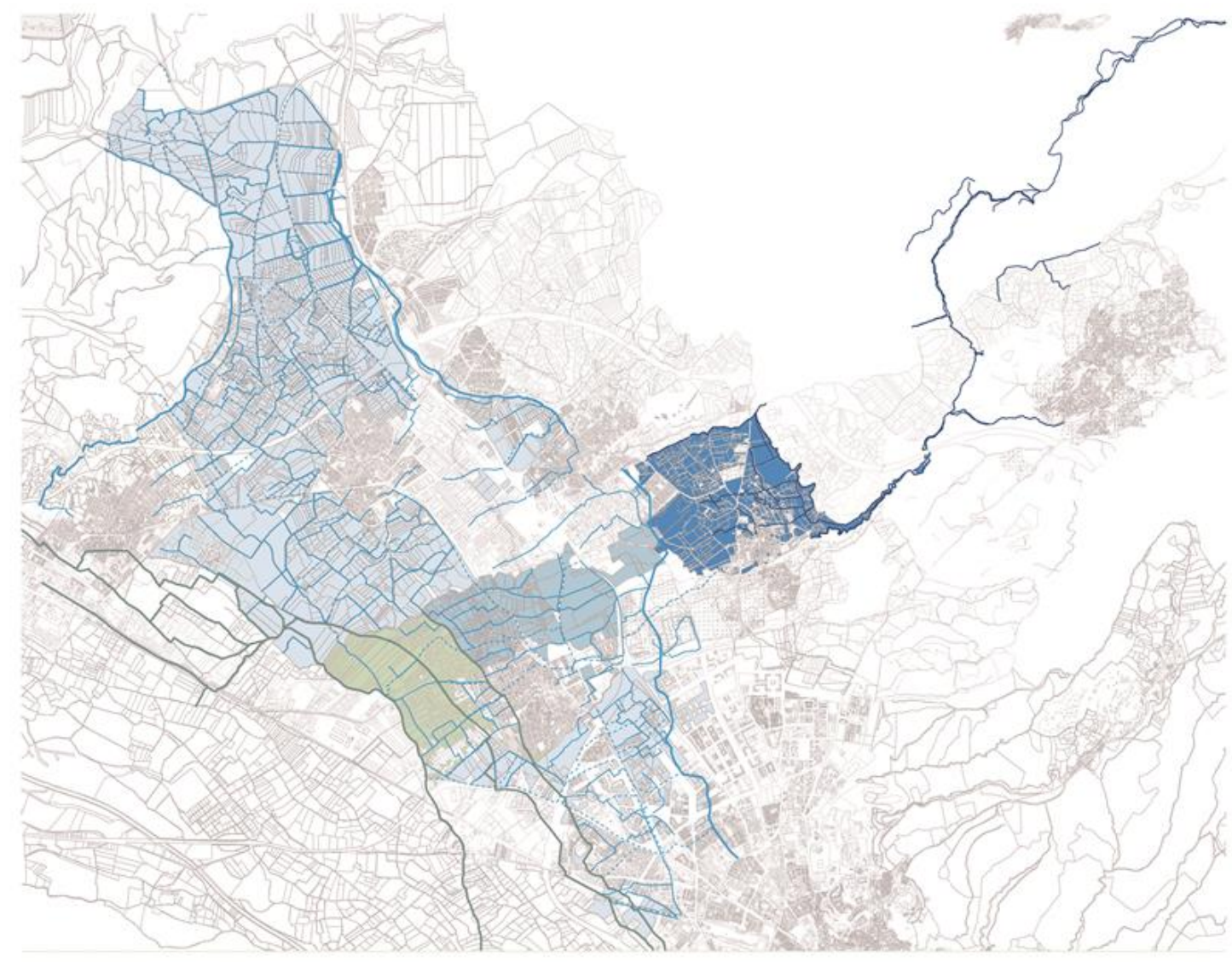

Nuevos Regadios del Canal de Albolote y su superposición con los regadíos tradicionales del Canal de Fardes y la Acequia Gorda del Genil.

\footnotetext{
58. Área regada por el Canal de Fardes

Área regada por el Canal de Albolote sobre regadíos historicos de Fardes

Área regada por el Canal de Albolote sobre regadíos historicos de la Acequía Gorda

A. Área regada por el Canal de Albolote nuevos regadíos

En la ilustración están representados los trazados de las acequias principales y sus ramales, junto a las zonas que actualmente riegan. Este trabajo se encuentra en fase de elaboración. Una vez realizado el levantamiento completa de la red de acequias existentes y llevado acabo el reconocimiento sobre el plano catastral de aquellas parcelas que son regadas, la segunda fase será detectar los cambios producidos en la red y la transformación de los usos del suelo. A simple vista, observamos como parte de las conducciones de agua se encuentra ocultas bajo la urbanizacion sustituyendose zonas de regadio por crecimientos residenciales e industriales o como las carreteras imponen su trazado de manera ajena a la parcelación agraría.
}

Fig. 7. Canal de Albolote y su relación con otras acequias. CCelia Martínez Hidalgo 
Un ejemplode la Vega de Granada podría ser el de la antes referida Acequia del Jacín, donde los turnos de riego están organizados según dulas de doce horas, dulas de mañana desde la puesta del sol hasta las cuatro de la tarde del día siguiente y dulas de tarde desde las cuatro al alba. Este sistema ha permanecido inalterable junto a otros privilegios de aguas existentes dentro del ámbito de riego, como zonas sin derechos de riego (los pagos secos) o parcelas con prioridad de riego o riego con agua procedentes de otras acequias.

Mención especial merecen también los acequieros, los cuales deberían considerarse como tesoros vivos, dado el conocimiento que atesoran de todo la historia productiva del espacio agrario irrigado en el que ejercen su competencia. También tendrían cabida otros tipos de bienes intangibles relacionados con la cultura del agua: refranes, celebraciones, toponimia, juegos, etc.

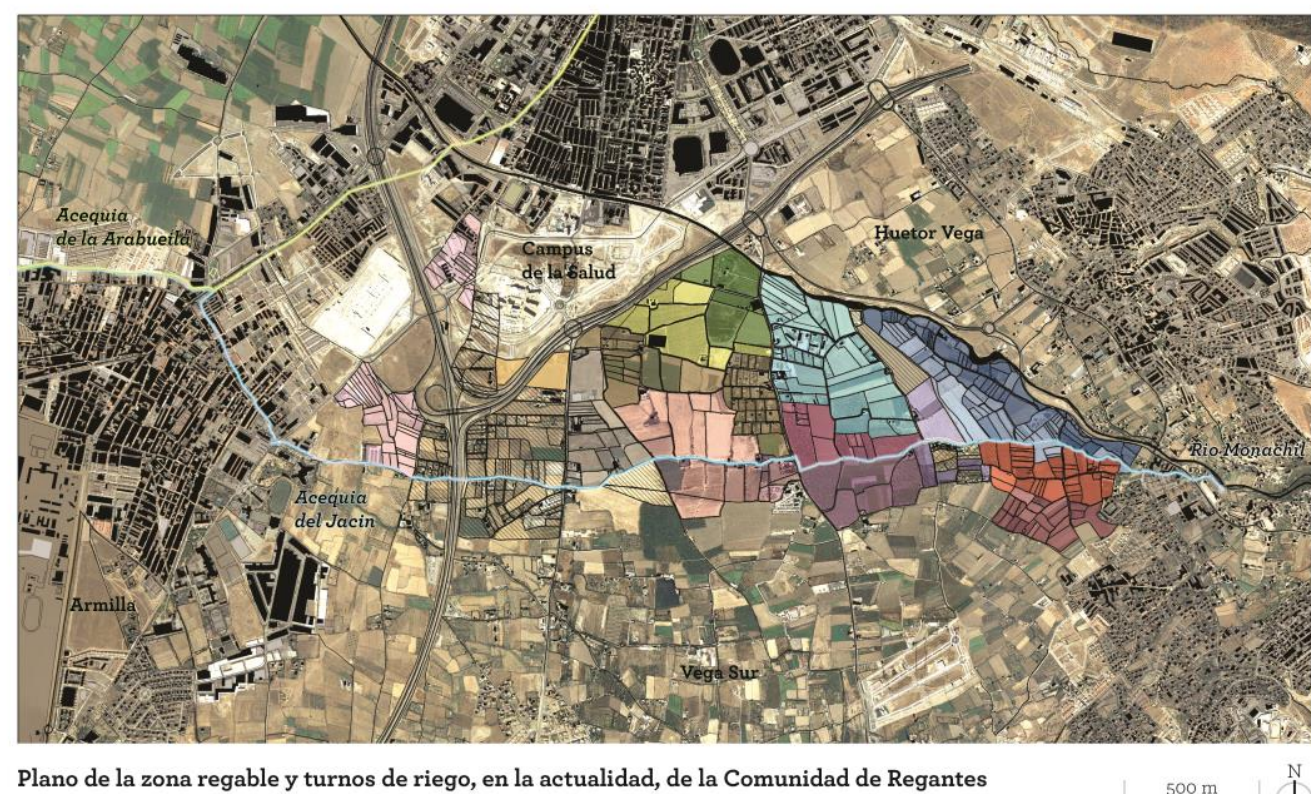

Plano de la zona regable y turnos de riego, en la actualidad, de la Comunidad de Regantes de la Acequia del Jacin del Rio Monachil sobre ortofoto y parcelario catastral 2012

Z 7 Superficie regada por la Dula del lunes por la mañana

Superficie regada por la Dula del lunes por la tarde

14 Superficie regada por la Dula del martes por la mañana

1 Superficie regada por la Dula del martes por la tarde

بffil Superficie regada por la Dula del miercoles por la mañana

13. Superficie regada por la Dula del miercoles por la tarde

Superficie regada por la Dula del jueves por la mañana

IIIIV Superficie regada por la Dula del jueves por la tarde

\uperficie regada por la Dula del viernes por la mañana

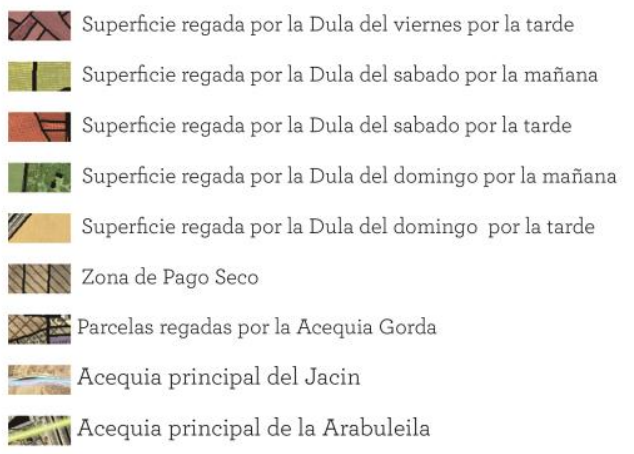

Fig. 8. Organización del riego por dulas en la Acequia del Jacín. CCelia Martínez Hidalgo 
a) Valores naturales.

Aquí habría que distinguir entre los valores naturales de los recursos hídricos de los que se nutren los sistemas de riego (ríos, acuíferos, manantiales, charcas, etc.) y, especialmente, el de las acequias y demás elementos del sistema hidráulico. En su conjunto podemos identificar los siguientes valores :

- La conformación de ecosistemas acuáticos específicos: flora acuática, invertebrados, anfibios, aves acuáticas, etc.

- El funcionamiento de las acequias y sus franjas laterales naturales como corredores ecológicos entre espacios por lo general altamente modificados desde el punto de vista natural.

- La creación de formaciones vegetales ribereñas que sirven de refugio y alimentación para multitud de especies de flora y fauna.

- A estos valores habría que unir los del propio recurso del agua, cuya calidad, además de su cantidad, debe preservarse como garantía de permanencia del sistema y de su autenticidad y valor.

En el caso de la Vega de Granada quisiéramos destacar dos grandes valores naturales: por un lado, el del impresionante acuífero que subyace en el subsuelo de la Vega y la imprescindible labor de recarga del mismo que hace el sistema de riego y, por otro lado, el de los singulares ecosistemas generados en torno a los canales (las denominadas "madres") construidos en la zona Oeste de la Vega para drenar el agua subterránea y dirigirla hacia las acequias construidas a partir de ellos (Canal de San Juan, Canal de la Reina, Canal Ojos de Viana, Madres de Rao, etc.).

Centrándonos en el acuífero de la Vega de Granada, señalar que éste es uno de los más importantes de Andalucía, en razón de su extensión, $200 \mathrm{~km}^{2}$, pero sobre todo por la cuantía de sus recursos renovables, que son del orden de $150 \mathrm{hm}^{3} /$ año (en continuo descenso en los últimos años). Y ello sin contar con el volumen de reservas almacenadas, de cerca de $1.000 \mathrm{hm}^{3}$. Lo más genuino y característico de este acuífero (común a otros ligados a vegas de ríos activos) es que la mayor parte de su alimentación procede de la infiltración de las aguas derivadas y aplicadas en el regadío. Con buen drenaje, las aguas que circulan por los cientos de kilómetros de acequias tradicionales sin revestir, así como las aplicadas por gravedad a las parcelas de riego se infiltran en buena parte en el subsuelo. Especial trascendencia tienen para la recarga los riegos por inundación de choperas y las prácticas (cada vez menos utilizadas) de "riegos de invierno", "entarquinados" y "careos".Tener bien alimentado a este embalse subterráneo es fundamental por muchas razones, pero muy en particular por ser pieza clave y estratégica en el suministro urbano y agrícola en situaciones de sequía e incluso de emergencia (Castillo, 1995). 


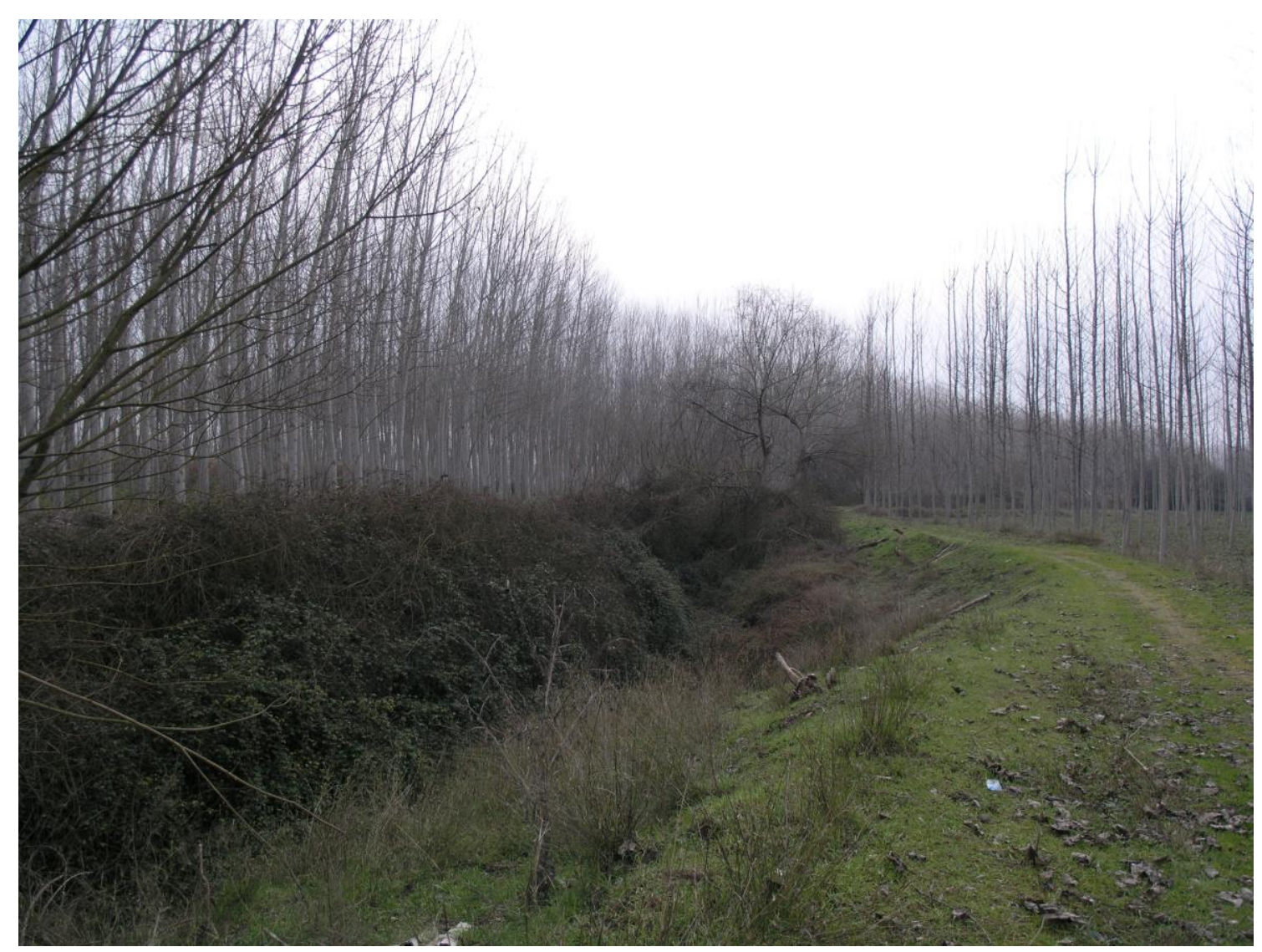

Fig. 9. Canal de la Fuente de la Reina (Santa Fe). CJosé Castillo Ruiz.

\section{c) Valores ambientales y paisajísticos.}

Son valores derivados de la interrelación de las dimensiones natural y cultural analizadas anteriormente y que están relacionados con las cualidades que tienen los sistemas hidráulicos para la percepción y disfrute del paisaje. En este sentido destacan, por un lado, el bienestar ambiental que genera el agua (suavización de las temperaturas, rumor, vegetación, etc.) y, por otro lado, las posibilidades de conocimiento y disfrute del paisaje que permiten los recorridos lineales que marcan las acequias. Especialmente relevantes son en este sentido los caminos de los acequieros, esos caminos situados de forma paralela a las acequias y cuya construcción es, en la mayoría de los casos, obra del tiempo; del continuado tránsito nocturno y diurno del acequiero y los regantes en su cotidiana tarea agrícola.Unos caminos que además ofrecen una lectura del territorio absolutamente respetuosa y armónica (la marcada por el suave discurrir del agua guiada por la ley de la gravedad), además de muy diferente a la marcada actualmente por las infraestructuras, y, por tanto, de un gran potencial para el disfrute y conocimiento de los ciudadanos. 


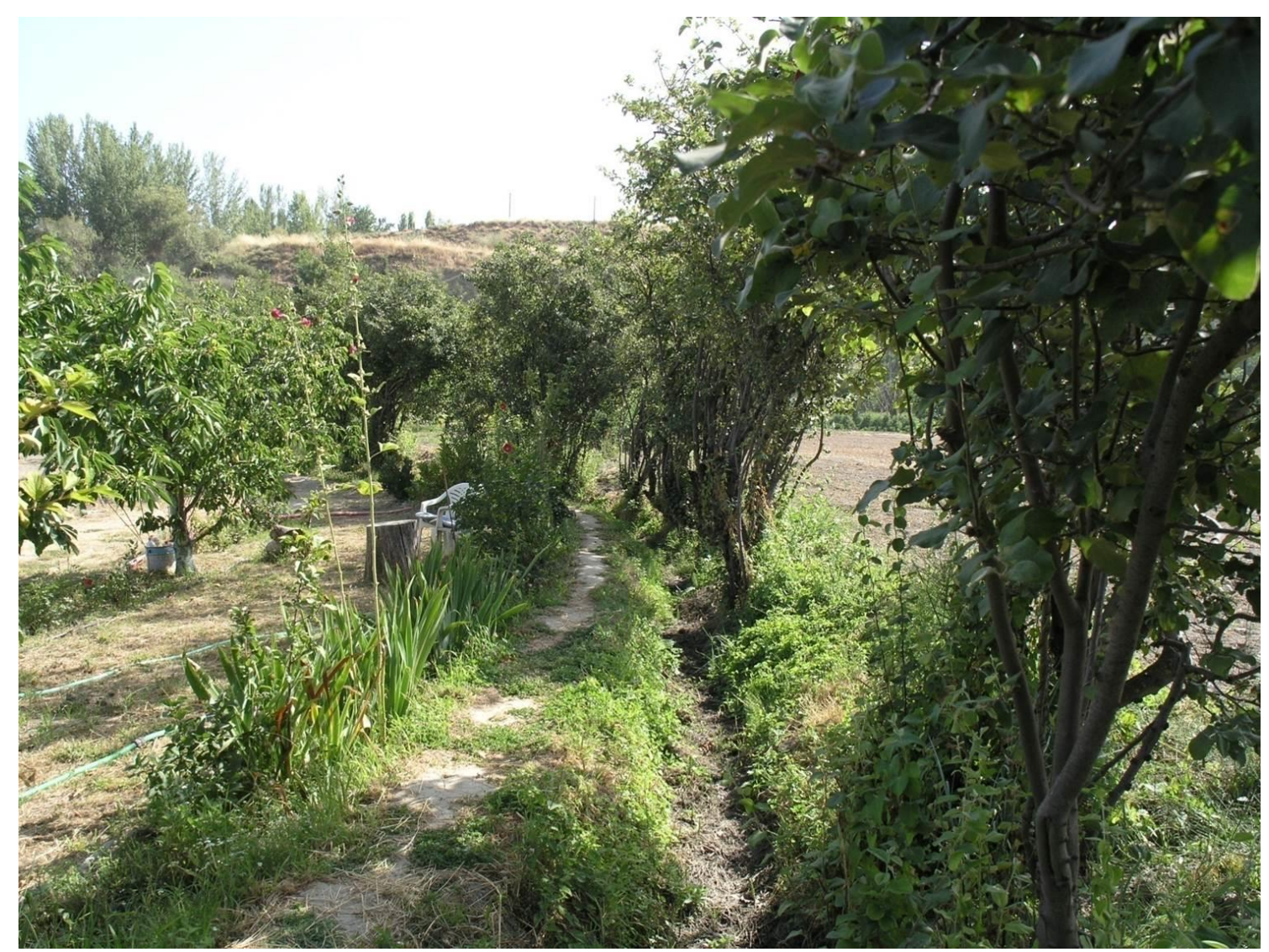

Fig. 10. Camino de acequiero en un ramal de la Acequia del Albaricoque (Monachil, Granada). CJosé Castillo Ruiz.

Centrándonos en la Vega de Granada, tenemos que señalar que la capacidad paisajística de las acequias es muy elevada a pesar del escaso desnivel de todo el espacio irrigado, lo que reduce (con las excepciones de las situadas en la parte más elevada de los valles del río Dílar o Monachil) su potencialidad como posibles miradores. Esta capacidad viene determinada sobre todo por la amplitud del campo de visión que de forma general existe en la Vega debido a su conformación como extensa y llana cuenca sedimentaria rodeada de glacis y montañasy por la capacidad para reconocer y adentrase en los elementos constitutivos de la Vega (especialmente las zonas de cultivo), incluido el contacto con los agricultores y su actividad diaria. Por lo que respecta a su capacidad de articulación territorial, quisiéramos señalar la diferente circulación que permite el tránsito por las acequias respecto a la comunicación vial existente entre Granada y su área metropolitana. Permite por ejemplo seguir la dirección de los cauces de los ríos, lo que plantea una recorrido longitudinal del territorio (y muy natural) hoy apenas permitido a excepción de la ribera del río Genil; posibilita una conexión de los núcleos de población en función de su vinculación histórica a través de los sistemas de riego (por ejemplo entre Monachil, Cájar y La Zubia), en la actualidad perdida pues la relación es radial respecto a Granada y no tanto entre sí; permite entender la relación de los asentamientos urbanos, especialmente Granada, con su territorio, percibiendo el proceso de crecimiento de estos núcleos y su progresiva desvinculación del mismo, etc. A todo ello debemos sumar el hecho de que a través del tránsito por las acequias es cómo se puede apreciar la verdadera dimensión estructurarte del territorio que tiene el sistema hidráulico y su imprescindible inclusión en cualquier instrumento de ordenación o protección del mismo. 


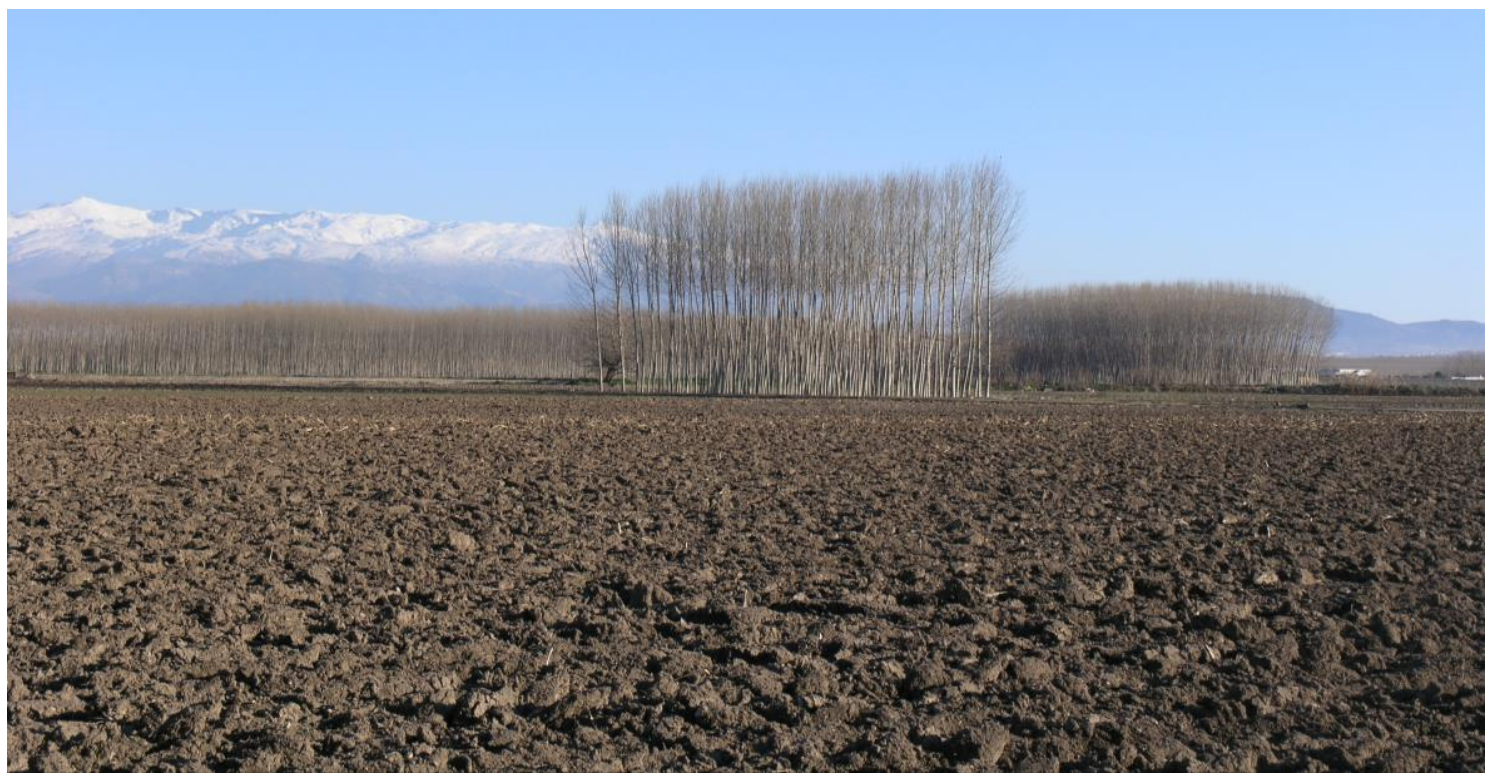

Fig. 11. Paisaje invernal desde el Cortijo del Alitaje (Pinos Puente). CJosé Castillo Ruiz.

\section{d) Dimensión funcional o valor agricola.}

Todos estos valores señalados hasta ahora quedan condicionados o supeditados al valor principal que debe justificar su reconocimiento patrimonial, el agrario, que, en este caso, se concreta en su funcionalidad como sistema de riego. Debe observarse, como sucede con el Patrimonio Agrario en su conjunto, no como un valor más sino como un elemento consustancial a su naturaleza patrimonial, por lo que su uso como tal sistema resulta un indicador fundamental para determinar la relevancia patrimonial del mismo. Esto supone incluir también los valores económicos o productivos comunes a todos los bienes agrarios.

En el caso de la Vega de Granada, ya hemos señalado cómo el mantenimiento de la actividad agrícola es uno de sus principales valores (y avales) patrimoniales de la misma, por lo que su continuidad, además de una exigencia para su preservación, podría ser una herramienta para el desarrollo económico y social de toda la zona, ya que el potencial productivo de la misma es enorme, sobre todo si se vincula (a través de diferentes mecanismos de comercialización) con la capacidad (y sin duda también deseo de hacerlo) de consumo de los cientos de miles de habitantes del área metropolitana de Granada.

e) La dimensión histórica de los valores patrimoniales de los sistemas históricos de riego. Las dificultades para su reconocimiento y valoración

Un hecho importante a considerar es que todos estos valores identificados (especialmente los culturales que son los determinantes en la fijación de la dimensión patrimonial de los sistemas de riego) deben observarse desde una perspectiva histórica(o de pasado), cuestión ineludible en la caracterización de cualquier bien integrante del Patrimonio Cultural y que en el caso de los regadíos históricos presentan una importante singularidad derivada de la necesaria continuidad funcional en el presente de unos sistemas que se corresponden con unas condiciones tecnológicas y funcionales prácticamente perdidas en la actualidad (debido a la mecanización y la introducción de nuevos sistemas de riego). Aunque puede resultar muy difícil mantener o, en muchos casos, recuperar estas condiciones tecnológicas y funcionales históricas, en este caso (y a diferencia de lo que sucede con la rehabilitación de un edificio histórico) debe hacerse todo lo posible por conseguirlo, ya que en ellas se 
contienen los valores de territorialidad y sostenibilidad tan determinantes en la valoración patrimonial de un sistema histórico de riego.

El reto que deberemos abordar desde las políticas de protección será el de determinar cuáles deben ser los parámetros concretos bajo los cuales debe mantenerse el sistema tradicional de riego. Desde nuestro punto de vista, estos parámetros deben vincularse con la necesaria normalización (patrimonial y funcional) que debe hacerse de la agricultura tradicional (como alternativa o complemento a la agricultura ecológica) y donde el mantenimiento del sistema de riego tradicional resulta fundamental.

Si bien no podemos exigir que se siga cultivando exactamente igual que en épocas pasadas, sí que es legítimo determinar, por ejemplo, que en los espacios agrarios históricos se sigan manteniendo los derechos históricos sobre el agua (amenazados por las actuales políticas europeas y españolas de agua), las formas de captación del agua (con los complementos hídricos que sean necesarios y acordes con las capacidades de los diferentes tipos de acequias), la distribución del agua a través de acequias no entubadas -preferiblemente de tierra- y continuamente mantenidas, la organización autónoma del riego en cada acequia, la forma de riego en superficie (principal caballo de batalla en la protección de estos sistemas de riego) o, en la lado contario, prohibir, además de todo lo que impida lo anterior, que las acequias, como sucede incomprensiblemente con las de la Vega Granada, se utilicen para verter las aguas residuales de la mayoría de las localidades colindantes.

A esta cuestión de la dimensión histórica debemos añadir la dificultad que supone diferenciar entre aquellos sistemas de riego que podemos considerar históricos (y por lo tanto susceptibles de proteger) y aquellos otros que no lo son por su contemporaneidad (y que pueden ser nuevos espacios irrigados de forma independiente o vinculados a otros sistemas históricos). Desde nuestro punto de vista, el criterio a seguir debe ser el mismo que para cualquier otro bien cultural, incluido el referido a los añadidos modernos incorporados a un sistema histórico: admitir cualquier sistema hidráulico con independencia de su fecha de construcción siempre que disponga de forma relevante de los valores culturales y naturales antes señalados.

En el caso de la Vega de Granada nos encontramos con una situación muy singular en relación a esta cuestión, ya que, como antes indicábamos, en torno a la mitad del siglo XX se produjeron dos ampliaciones muy significativas de la zona históricamente irrigada a través de la construcción del Canal de Albolote y del Canal del Cacín. Aunque son realidades diferentes, ya que el canal del Cacín lo que hace es irrigar una zona tradicionalmente de secano, mientras que el Canal de Albolote lo que hace es reordenar áreas deficientemente e irregularmente irrigadas a las que se unen otras zonas que eran de secano, consideramos que ambas áreas de riego nuevas deben incluirse dentro del espacio a preservar de la Vega de Granada. Por varias razones: la primera porque corresponden a una época que podemos considerar ya como histórica, aunque obviamente no con la antigüedad, y por tanto relevancia, que la época medieval. La segunda, porque estamos ante una infraestructura de gran extensión y complejidad, lo que le otorga un valor técnico importante, sobre todo si tenemos en cuenta que el punto de captación del agua se encuentra muy alejado de la zona irrigada (el pantano de los Bermejales en el caso del Canal del Cacín y el manantial de Deifontes en el caso del Canal de Albolote). Y la última, porque hay una intención de vinculación, de articulación con el sistema histórico de riego existente en la Vega de Granada en un deseo de continuar, de sumarse (y por lo tanto de respetar) al mismo, lo que da un valor de continuidad histórica de gran interés. El Canal del Cacín 
amplía el límite de la Vega hacía el Sur, subiendo significativamente la cota de irrigación. El Canal de Albolote por su parte, situado al norte de la Vega, se encaja en una cota intermedia entre los regadíos tradicionales de Fardes-Morquí- Fuente Chica y la amplia zona regada por la acequia Gorda del Genil. Como podemos observar en la Ilustración n ${ }^{\circ}$ 7,el Canal principal de Albolote dibuja la cota de nivel recogiendo los desagües de las comunidades situadas en cotas superiores y las escorrentías de los barrancos de manera perpendicular; mientras, en su contacto con la acequia Gorda del Genil, vemos como los nuevos y los antiguos ramales se superponen y conectan formando una red totalmente unitaria.

Aunque los valores reseñados hasta aquí son muchos y de gran relevancia, sin embargo su reconocimiento y percepción, especialmente por parte de la sociedad, resulta muy dificultosa. Por varias razones.

La primera de ellas es común a todos los bienes que integran el Patrimonio Agrario y es consecuencia de su condición agraria, la cual tiene en nuestra sociedad lamentablemente una escasa consideración.

La segunda razón, y ya específica de los sistemas de riego, tiene que ver con su materialidad. A excepción de algunos elementos singulares del sistema como puentes, presas, acueductos, norias, etc., los cuales por lo general presentan una riqueza material importante (de ahí el valor histórico-artístico o técnico que generalmente se les suele reconocer cuando se procede a su declaración ), el resto de elementos del sistema, especialmente las acequias, presentan una materialidad que podríamos calificar como pobre o poco relevante, ya que muchas de ellas son canales excavados en la tierra con apenas estructuras de refuerzo, contención o impermeabilización. Si a esto le unimos el alto grado de modificación que ha experimentado en muchos casos esta materialidad (en la actualidad gran parte de los trazados están entubados o canalizados con cemento), la valoración de estos sistemas se hace aún más difícil.

Una última razón tiene que ver con la dificultad que existe para poder percibir de forma conjunta, clara y relevante los elementos patrimoniales de un sistema hidráulico de riego. Y ello debido, por un lado, a su difuminación por el territorio (generalmente muy extenso además) y, por otro lado, a su naturaleza superficial y plana que apenas les hace destacar sobre la tierra. No es de extrañar en este sentido que los sistemas hidráulicos más valorados socialmente (y objeto de los primeros reconocimientos patrimoniales) sean aquellos que perceptivamente son más reconocibles, tal y como sucede con los muy apreciados espacios agrarios aterrazados 8 .

\footnotetext{
8 En este sentido cabe destacar los paisajes culturales agrarios declarados por la UNESCO Patrimonio Mundial donde tienen gran presencia estos cultivos aterrazados. Es el caso del Paisaje Cultural de los Campos de Arrozales en Terrazas (Filipinas, 1995) y el Paisaje Cultural de la Provincia de Bali: el Sistema Subak como testimonio de la Filosofía Tri Hita Karana, (Indonesia, 2012). A esto hay que unir la especial consideración patrimonial que existe de los espacios agrarios irrigados de montaña, compuestos en su mayoría por sistemas de terrazas o bancales. Destacar al respecto la Alpujarra granadina, declarada en gran parte Bien de Interés Cultural y ahora propuesta para su declaración como Patrimonio Mundial. En este mismo contexto se podrían incluir el reconocimiento internacional de los espacios aterrazados de los grandes yacimientos arqueológicos de la cultura prehispánica en la zona de los Andes, con la ciudad sagrada inca Machu Picchu a la cabeza.
} 


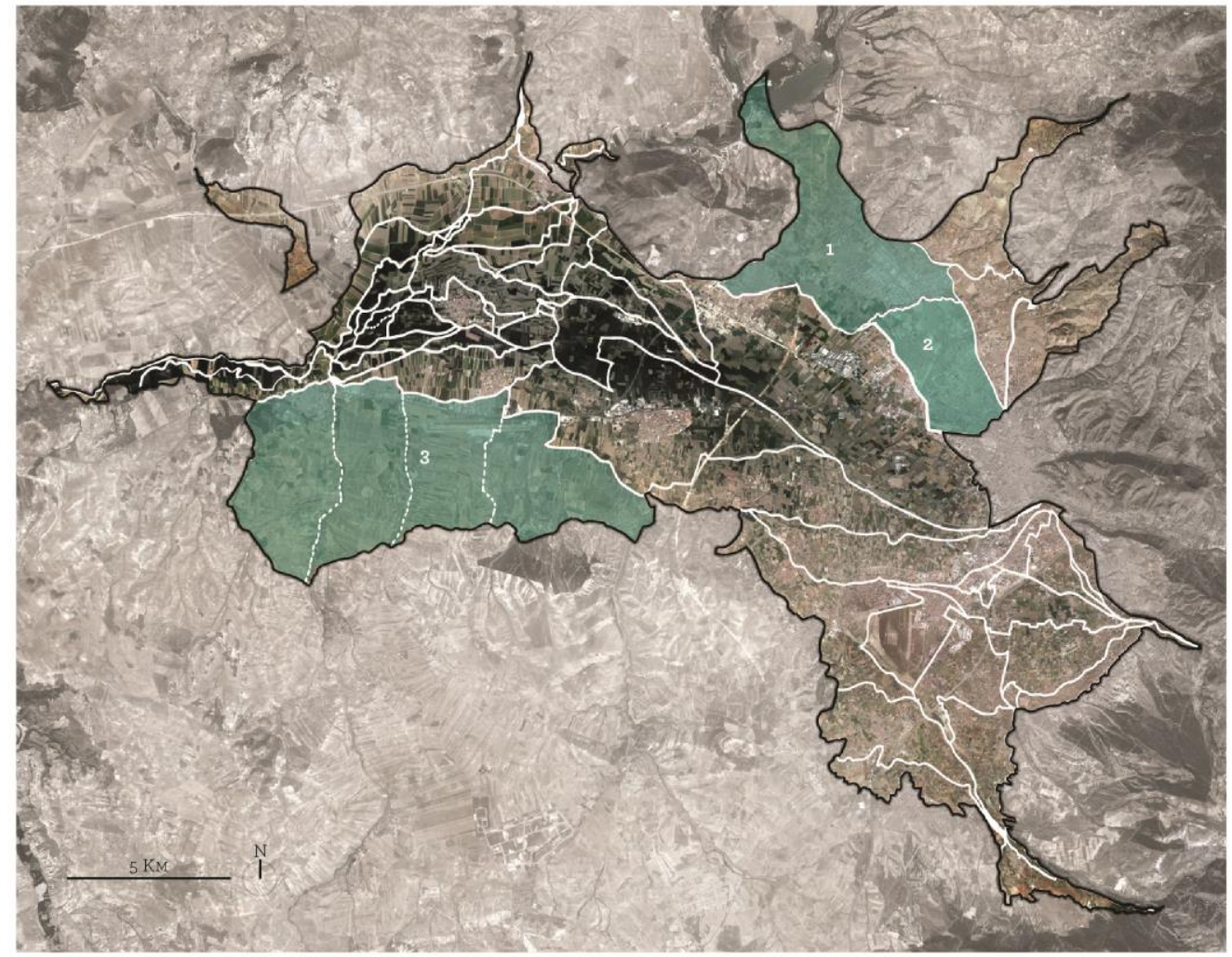

Nuevos Regadios del Cacín y de Albolote dentro del ámbito de la Vega de Granada sobre Ortofoto 2012

1. Nuevos regadíos del Canal de Albolote

2. Nuevos regadíos del Canal de Albolote, sobre regadiós historicos de Fardes y Morquí

3. Nuevos regadíos del Canal del Cacin

Fig. 12. Ampliación de la zona histórica de riego de la Vega de Granada. CCelia Martínez Hidalgo.

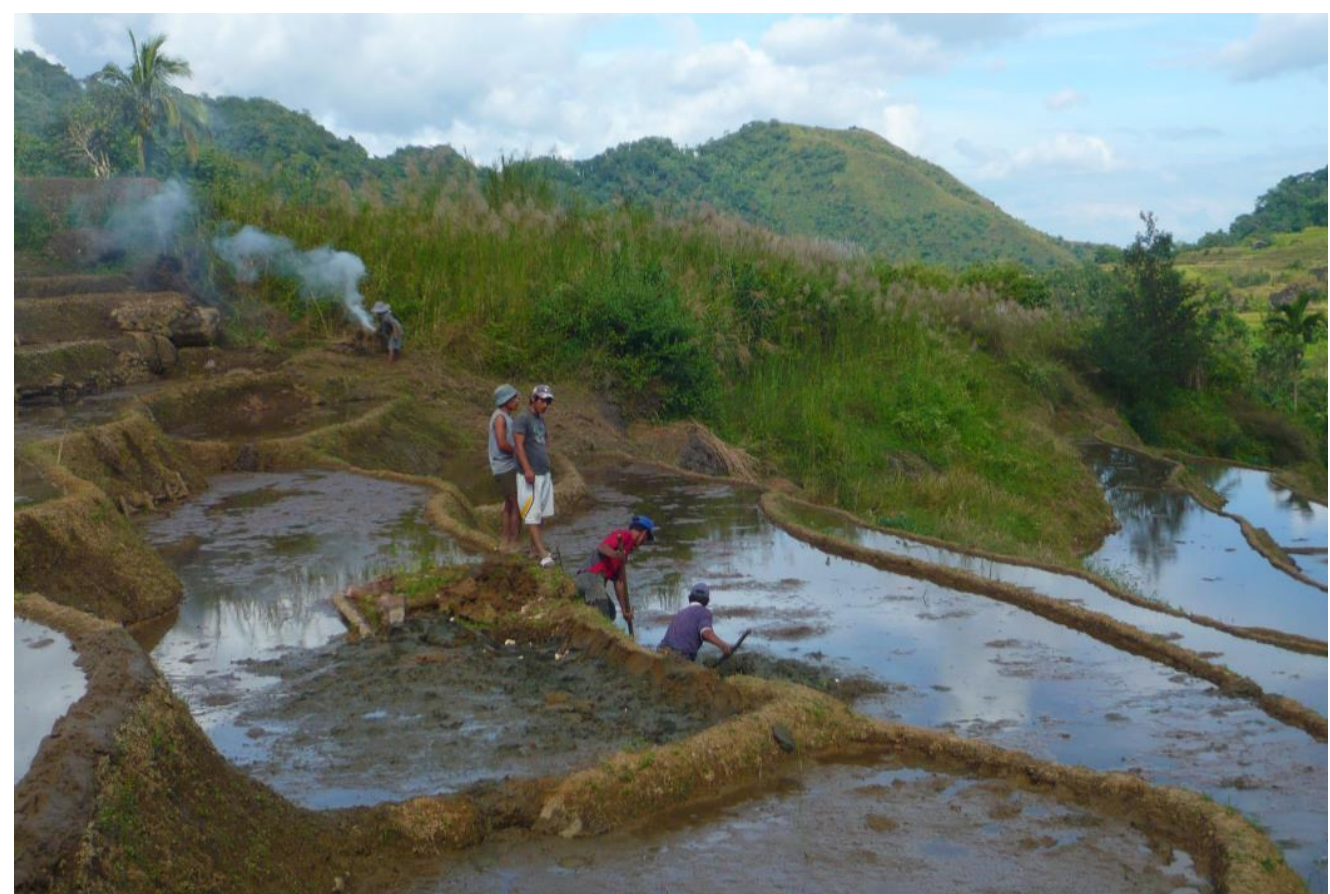

Fig. 13. Terrazas de arrozales de las Cordilleras Filipinas y aprendizaje del Hudhud, tradición narrativa milenaria asociada a la cosecha. CCelia Martínez Yáñez. 
Todas estas dificultades lo que ponen de manifiesto es la necesidad que existe de enseñar y divulgar el lenguaje de estos espacios (su forma y elementos constitutivos) y transmitir a la ciudadanía la importancia de sus valores (sobre todo los relacionados con la construcción histórica de un territorio), muchas veces poco perceptibles y reconocibles.

Desde luego en la Vega de Granada todas estas dificultades para la percepción y valoración se agrandan si tenemos en cuenta, como antes anticipábamos, lo extenso y plano del territorio ocupado y la ausencia de elementos hidráulicos de valor patrimonial singular. Por esta razón, los esfuerzos por explicar a todos los ciudadanos la riqueza patrimonial que subyace en la forma de construir el territorio a través de ese intrincado sistema de parcelas (de muy desigual tamaño y forma aunque por lo general de mediana o pequeña extensión) interconectadas y superpuestas a diferentes niveles y orientación para permitir el sutil y disciplinado discurrir del agua a lo largo de toda la superficie de riego, deben ser muchos y estar a la altura del ingenio, organización, esfuerzo e inteligencia de sus creadores y posterior continuadores.

\subsection{Criterios para su delimitación como un espacio patrimonial formalmente constituido}

El reconocimiento que aquí hacemos de los regadíos históricos como un tipo de bien inmueble de conjunto dentro del Patrimonio Agrario exige que se proceda a su formalización espacial, y de forma unitaria, como tal ámbito patrimonial a proteger. Esto plantea la cuestión de la delimitación de dicho espacio, la cual es uno de los obstáculos más importantes y difíciles de superar que tienen todos los bienes territoriales, y en particular, los agrarios. Por estas razones:

- La amplitud y dispersión en el territorio (sobre todo la extensiva y el secano) de la actividad agrícola y ganadera, lo que complica proceder a una delimitación y, sobre todo, someter a tan vasto territorio a un régimen de protección estricto.

- La variabilidad de los espacios agrarios en función de la explotación o no (temporal o definitiva) de los mismos.

- La interrelación con otras actividades, sobre todo en los ámbitos periurbanos.

La cuestión principal a dilucidar en este sentido es el alcance de la delimitación, es decir, si debe limitarse al trazado de los elementos hidráulicos, especialmente las acequias (y en este caso, si se reduce a las principales o se incluyen todas) o si se incorpora también todo el paisaje agrario (zona de cultivo, asentamientos urbanos, accidentes geográficos, etc.) conformado por el sistema.

Si nos remitimos a la naturaleza patrimonial de los regadíos históricos, extraemos que el elemento esencial del mismo es su funcionalidad agraria, por lo que de aquí se deriva que el ámbito objeto de protección debe ser la globalidad del territorio (y de todos sus elementos constitutivos) en el que se desarrolla la actividad agraria (y derivadas) generada por dicho sistema, es decir la huerta, vega o espacios agrarios similares. Esto permitiría incluir en una misma delimitación todos aquellos sistemas de riego que aparecen interrelacionadas en un espacio agrario determinado, conformando una intencionada y reconocible unidad como asentamiento humano (urbano y territorial). Todo ello sin olvidar que, efectivamente, el elemento fundamental en la construcción de ese paisaje es el sistema hidráulico por lo que debe ser él el que determine y formalice los límites patrimoniales del bien objeto de protección. Un sistema que debe incluir no sólo la red de acequias y demás elementos de 
captación y distribución del agua, sino todo el territorio irrigado tanto en su dimensión material (parcelas o hazas) como inmaterial (dulas o pagos). Y ello con independencia de que en algunos casos puedan incluirse otros espacios o bienes fuera de los límites regados e íntimamente vinculados con el mismo.
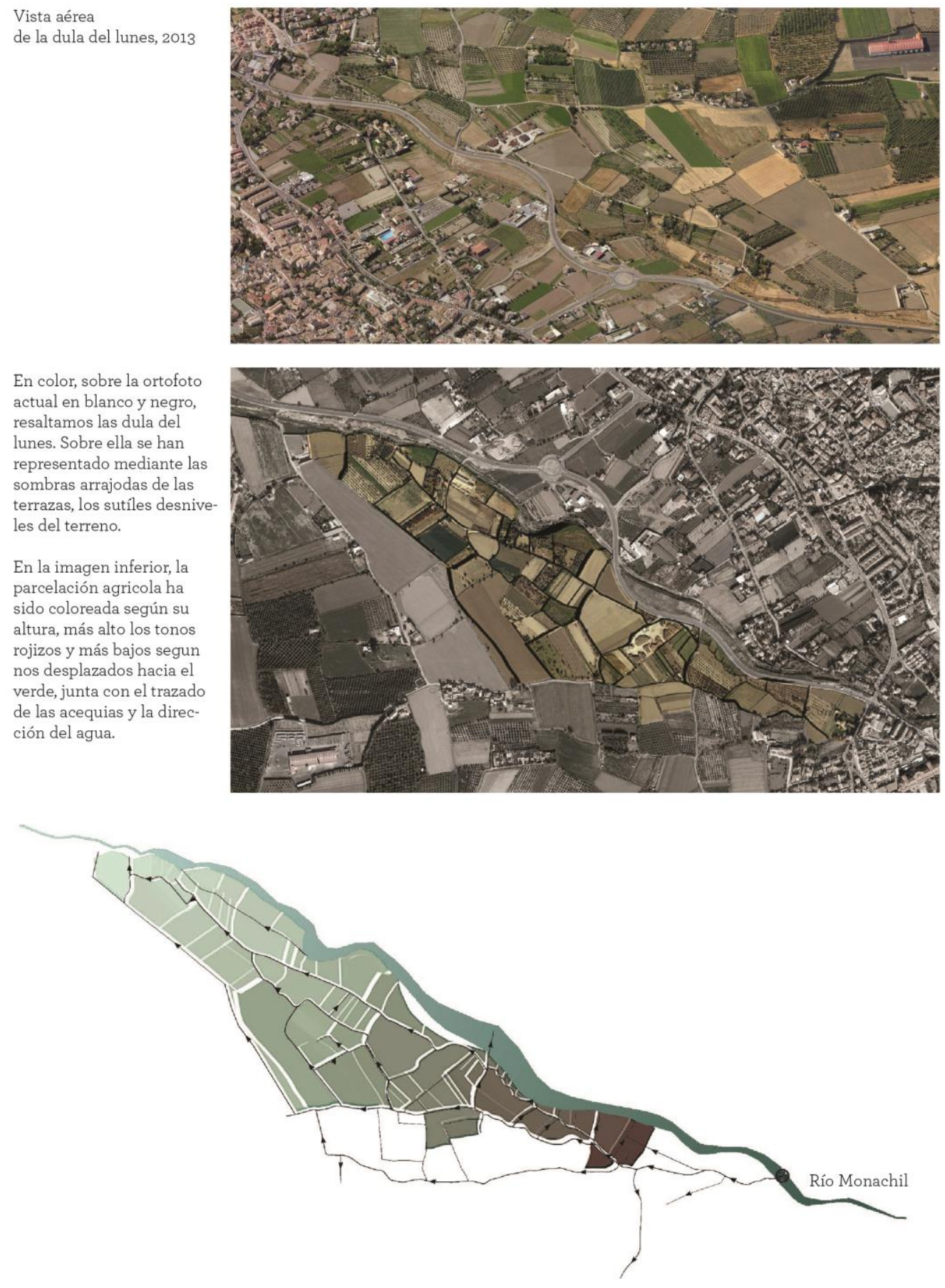

Dula del Lunes perteneciente a la Comunidad de Regantes del Jacín, Río Monachil. El trabajo de adecuación del terreno : terrazas y acequías.

Fig. 14. Distribución de las terrazas de cultivo en la Acequia del Jacín. CCelia Martínez Hidalgo. 
Esta es la situación que nos encontramos en la Vega de Granada. Aunque se trate de un espacio de una gran extensión territorial e incluso de una gran diversidad en cuanto a su conformación física, territorial, histórica e incluso agraria, sin embargo dispone de una indiscutible unidad espacial y cultural, cuya máxima expresión es el reconocimiento social de dicha unidad y su conversión en una importante seña de identidad de los granadinos junto con la Alhambra y Sierra Nevada.Esta unidad como asentamiento territorial, que es consecuencia de su constitución física (como depresión del río Genil) e histórica (área de influencia de la ciudad de Granada) es lo que nos permite (y exige) considerar de forma unitaria todo el sistema hidráulico que la estructura, el cual es de un gran diversidad y complejidad, aunque plenamente interrelacionado.De esta forma disponemos de un criterio muy objetivo y riguroso (y de gran seguridad jurídica) para delimitar la Vega de Granada como espacio a proteger: el espacio irrigado por todas las acequias y cuya línea envolvente sería la de los límites externos de las mismas. Esto no significa, como sucede con cualquier otro espacio complejo objeto de protección (por ejemplo las ciudades históricas), que todos los elementos y espacios existentes dentro de esta envolvente queden sometidos al mismo régimen de protección, ya que dependerá del valor que dispongan de forma singularizada.

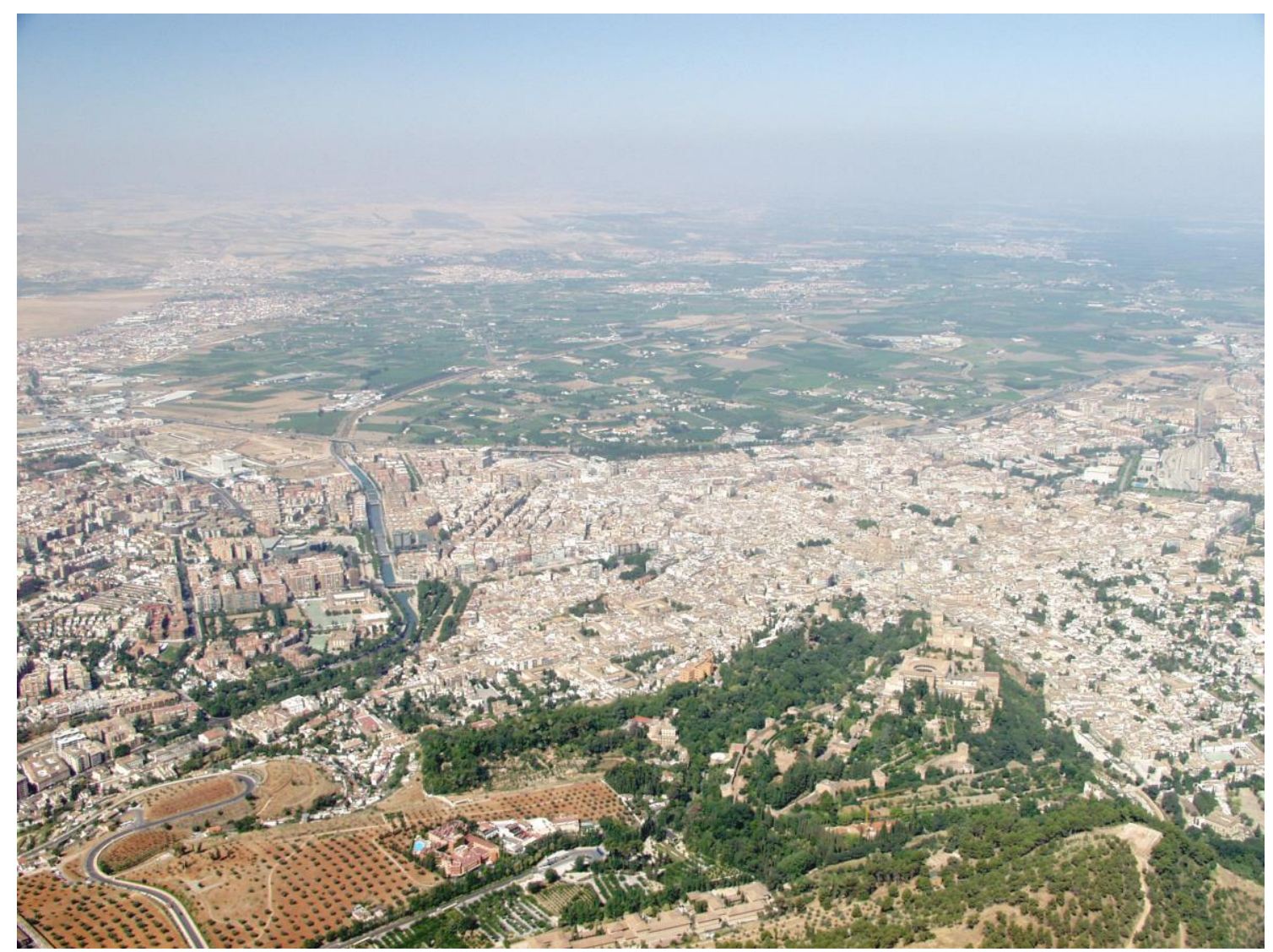

Fig. 15. Imagen general de la Vega de Granada y su implantación territorial. CPlataforma Salvemos la Vega.

\subsection{Mecanismos de protección}

La dimensión territorial (marcada por la linealidad del sistema) y funcional (que exige incluir la totalidad del espacio necesario para la producción agraria) que debe presidir la delimitación y protección de los regadíos históricos, según lo concluido anteriormente, nos lleva de nuevo a plantear las enormes dificultades que presenta la instauración de un sistema efectivo de protección dada la complejidad y diversidad de intereses existentes en 
estos espacios, razones por la cual las propuestas que se vienen haciendo en el ámbito académico y político se orientan mayoritariamente hacia un sistema difuso y concertado, aunque poco incisivo y muy variable, de actuación basado en la utilización del planeamiento urbano y territorial.

Desde nuestro punto de vista, y siguiendo los principios del Patrimonio Agrario, consideramos que es posible y viable la implantación de un modelo de protección derivado de la legislación de Patrimonio Histórico a través de algunas de las figuras legales de carácter territorial ya contemplados en nuestra legislación como la de Paisaje Cultural, Parque Cultural, Sitio Histórico, Lugar de Interés Etnológico o Zona Patrimonial.

Especialmente idóneo es el derivado de la figura de Zona Patrimonial (Verdugo, 2005), prevista en la Ley de Patrimonio Histórico de Andalucía de 2007 (LPHA), ya que contiene todas las claves que exige la protección de cualquier espacio agrario. Esta es su definición: "Son Zonas Patrimoniales aquellos territorios o espacios que constituyen un conjunto patrimonial, diverso y complementario, integrado por bienes diacrónicos representativos de la evolución bumana, que poseen un valor de uso y disfrute para la colectividad y, en su caso, valores paisajísticos y ambientales" (Art. 26.8 LPHA). Y estas son esas claves:

- Visión diacrónica e integral de todos los bienes y valores existentes en el territorio.

- Asimilación de la condición productiva y activa del mismo, lo que significa reconocer y preservar la dimensión funcional.

- El desarrollo de sus prescripciones de conservación a través (como sucede con todos los bienes inmuebles de conjunto) de los instrumentos urbanísticos y territoriales. El planeamiento se convierte, como sucede con los conjuntos históricos, en un instrumento fundamental, aunque subordinado a la declaración patrimonial, para la ordenación y preservación del espacio a proteger.

- Su vinculación a un sistema de gestión, ya que la declaración de una Zona Patrimonial puede llevar aparejada, según la norma andaluza, la creación de un organismo de gestión autónomo y supramunicipal, denominado Parque Cultural'.

Con independencia de la idoneidad de estas figuras (y otras que también pueden ser válidas como la de los conjuntos históricos o la del entorno, las cuales podrían incluir sin mayor impedimento espacios agrarios como componentes del ámbito espacial -urbano y territorial- protegido), desde el Proyecto Pago reclamamos la creación de una figura específica para la protección de los bienes agrarios en su dimensión territorial: el Lugar de Interés Agrario.

A modo de colofón de todo lo expuesto, quisiéramos reivindicar la relevancia cultural y natural de los sistemas de riego históricos o tradicionales y la necesidad de instaurar mecanismos de protección acordes con su naturaleza material y valorativa, lo que exige especialmente la puesta en marcha de acciones de reconocimiento y divulgación para la ciudadanía dada la dificultad que existe para percibir con claridad sus múltiples valores.

\footnotetext{
${ }^{9}$ Estas son las razones que han motivado que la Plataforma Salvemos la Vega de Granada haya optado por esta figura de protección, especialmente la ineludible vinculación entre protección y dinamización. Esta plataforma, que lleva activa desde hace casi dos décadas, es la que está canalizando y liderando el amplísimo y muy arraigado movimiento ciudadano en defensa de este espacio agrario histórico. En relación a la solicitud de declaración como BIC, ya ha sido presentada en cuatro ocasiones, la primera, en 2009 como Sitio Histórico, y las restantes (2010, 2011 y 2013) como Zona Patrimonial (la última con 20.000 firmas de apoyo). En todos los casos, la respuesta del gobierno andaluz ha sido desgraciadamente el silencio administrativo negativo.
} 


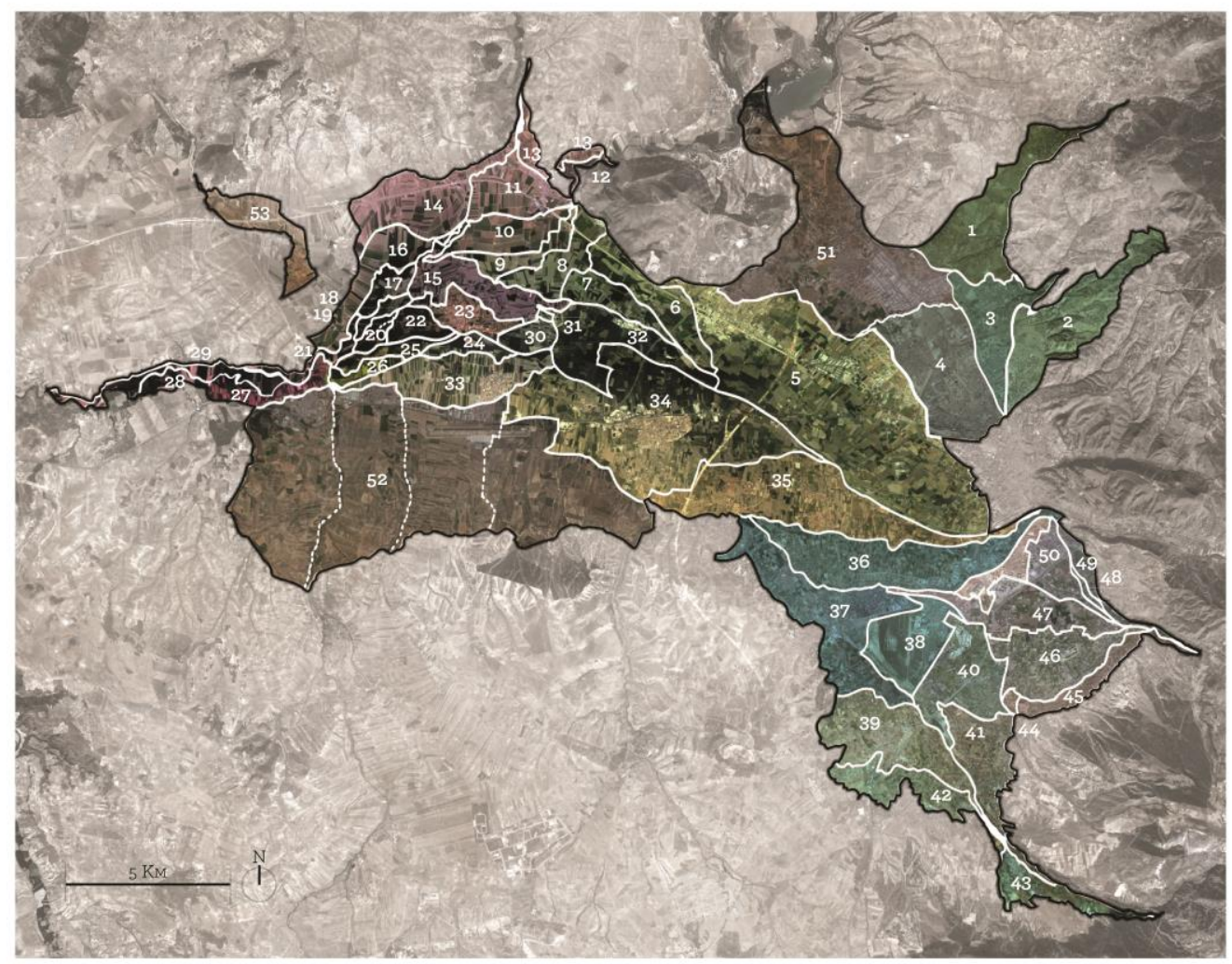

Distribución de las Comunidades de Regantes en la Vega de Granada sobre Ortofoto 2012 :

1. Güevejar
2. Morquí
3. Fardes
4. Canal de Albolote (también regada por Fardes y
Morquí)
5. Gorda del Genil
6. Jotayar de Atarfe
7. Fontana
8. Cruz de Granada
9. de Enmedio
10. Alitaje
11. Vadillo
12. del Cabo
13. las Zorreras
14. Velillos
15 Canal de San Jorge
16. Gorda deValderrubio
17. Huerta del Cubillas
18. Cardeal
19. Mocatea
20. Mocatea
21. Rambla Ancha
22. Fogariles
23. Fuente Vaqueros
24. Berrales o San Isidro
25. Razos de la Paz
26. Peujara

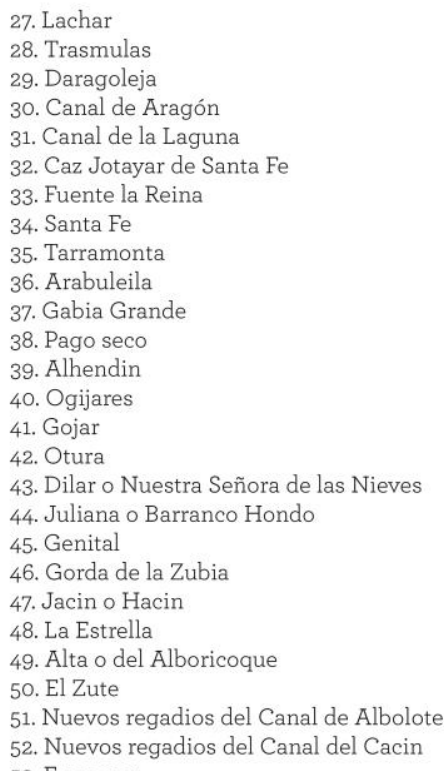

Fig. 16. Delimitación de la Vega de Granada a partir de la suma de los espacios irrigados por las diferentes Comunidades de Regantes. CCelia Martínez Hidalgo. 


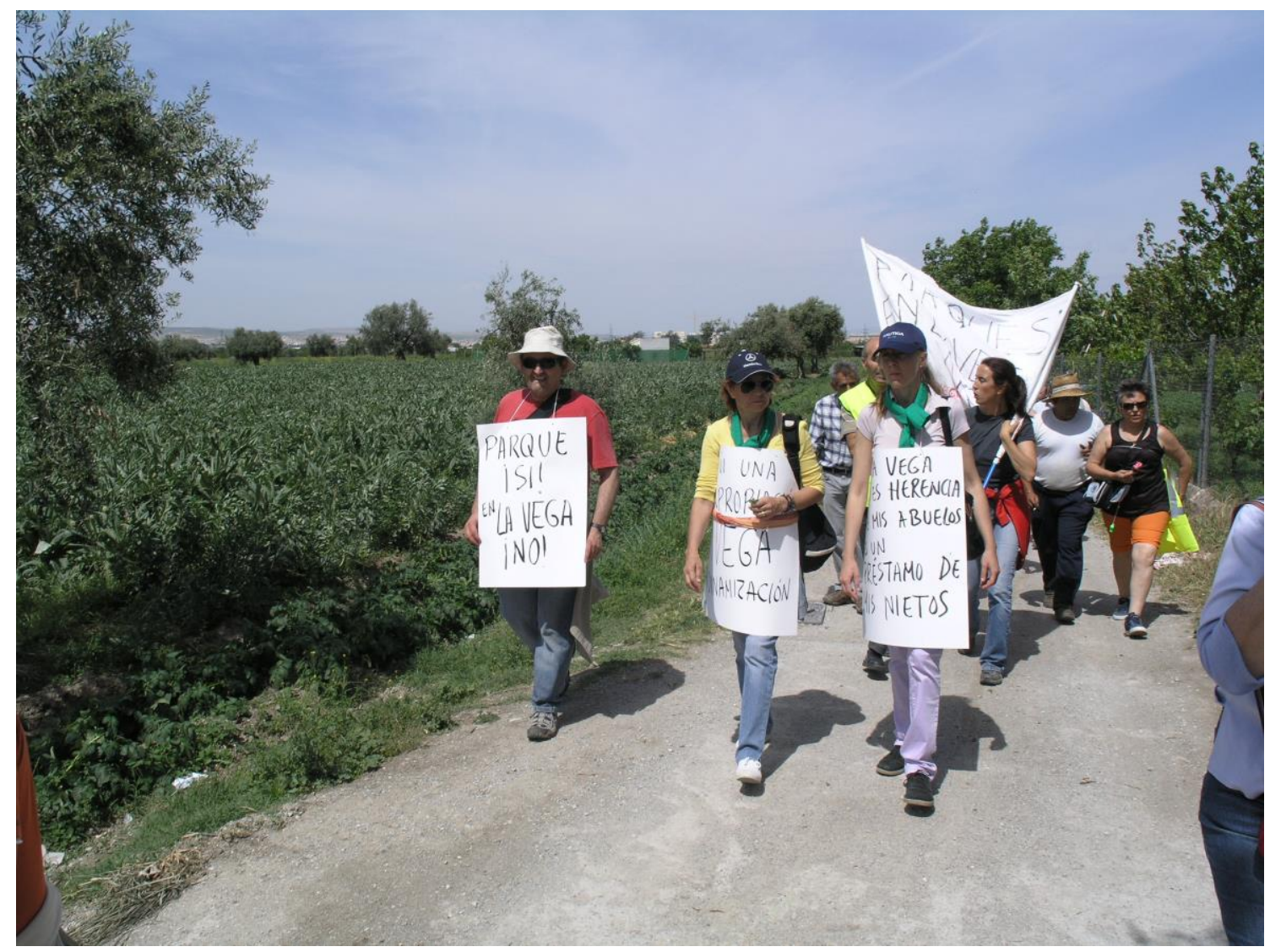

Fig. 17. Marcha ciudadana contra la instalación del Parque del Milenio en la Vega Sur (10 de mayo de 2009) CPlataforma Salvemos la Vega.

\section{Referencias}

Cabrera, D. Rojas M., JL. Gómez- Ordoñez (2010): Ordenación territorial del espacio fluvial del río Genil. Granada, Ministerio de Medioambiente, Medio Rural y Marino. http://hdl.handle.net/10481/5717

Castillo Ruiz, J. (2013):Carta de Baeza sobre Patrimonio Agrario, Sevilla, UNIA.

Castillo Ruiz, J., Cejudo García, E. (2010): «La Vega de Granada. La construcción patrimonial de un espacio agrario», Hermosilla Pla, Jorge (dir.), Los regadios históricos españoles. Paisajes culturales, paisajes sostenibles, Valencia, Ministerio de Medio Ambiente y Medio Rural y Marino, pp. 243-284.

Castillo Ruiz, J., Cejudo García, E. y Ortega Ruiz, A. (eds.) (2009):Patrimonio bistórico y desarrollo territorial, Sevilla, UNIA.

Castillo Martín, A. (2005): «El acuífero de la Vega de Granada. Ayer y hoy (1966-2004)», López Geta, J.A. et al. (eds.), Agua, Minería y Medio Ambiente: libro homenaje al profesor Rafael Fernández Rubio, Madrid, Instituto Geológico y Minero de España, págs. 161-172.

Castillo Martín, A. (1995): El embalse subterráneo de la Vega de Granada, uno de los más importantes de Andalucía. Tierra y Tecnología, 9: 37-42.

http://www.ugr.es/ aguas/archivos_pdf/articulos_aguas_vega/Tierraytecnol.pdf 
Espín Piñar, R., Ortiz Moreno, E. y Guzmán Álvarez, J. R. (2010), Manuel del acequiero. Parques Nacional y Natural de Sierra Nevada, Sevilla, Agencia Andaluza del Agua.

Fermín López, J. y Cifuentes Vélez, E. (2009): «Lugares de nuestro pasado común: la definición del interés patrimonial del territorio», Castillo Ruiz, José, Cejudo García, Eugenio y Ortega Ruiz, Antonio (eds.), Patrimonio histórico y desarrollo territorial, Sevilla, pp. 138-167.

Espinar Moreno, M. (1990): «Consideraciones sobre el regadío de la Vega de Granada. Repartimientos musulmanes (siglos XII-XVI)» Chronica nova: Revista de historia moderna de la Universidad de Granada, n 18 , págs. 121-154.

Hermosilla Pla, J. (2010): «Los regadíos históricos españoles. Reflexiones generales sobre el proceso de formación», Hermosilla Pla, Jorge (dir.), Los regadios históricos españoles. Paisajes culturales, paisajes sostenibles, Valencia, Ministerio de Medio Ambiente y Medio Rural y Marino, pp. 11-20.

Luna Díaz, J. A. (1988): «La Alquería: Un modelo socio-económico en la Vega de Granada. Aproximación a su estudio»,Chronica nova: Revista de historia moderna de la Universidad de Granada, nº 16, págs. 79-100.

Malpica Cuello, A. (1997): «Arqueología hidráulica y poblamiento medieval en la Vega de Granada», Fundamentos de Antropología, no 6-7, págs. 208-231.

Malpica Cuello, A. (dir.) (1995):El agua en la agricultura de Al-Andalus, Barcelona, Lumwerg.

Malpica Cuello, A. (2006): «El paisaje rural medieval en la Vega de Granada y la ciudad de Ilbira», Arqueología espacial, No 26, págs. 227-242

Martin Civantos, J. M. (2011): «The archaeology of irrigated spaces in southeast Spain during the medieval period», AA. VV, Processing, Storage, Distribution of food. Food in the medieval rural environment. Ruralia VIII, Turnhout (Belgium), Brepols, pp. 11-29

Martínez Yáñez, C. (2011):El patrimonio cultural: tendencias y proyecciones sociales y económicas. Estudio internacional y comparado del significado y uso del patrimonio ante los retos del siglo XXI, Madrid, Editorial Académica Española \& LAP LAMBERT Academic Publishing Gmbh\& Co.

Mata Olmo, R. y Fernández Muñoz, S.(2010): «Paisajes y patrimonios culturales del agua. La salvaguarda del valor patrimonial de los regadíos tradicionales», Scripta Nova. Revista Electrónica de Geografía y Ciencias Sociales. [En línea]. Barcelona: Universidad de Barcelona, vol. XIV, no 337. http://www.ub.es/geocrit/sn/sn-337.htm

Mata Olmo, R. y Fernández Muñoz, S. (2004): «La Huerta de Murcia. Landscape guidelines for a Peri-urban territory», Landscape Research, vol. 29, n. ${ }^{\circ}$ 4, pp. 385-397.

Martínez Hidalgo, C. y Pérez Córdoba. G.(2013):"La acequia del Fardes. Los caminos del agua como soporte estructurador del territorio". Comunicación en el II Congreso Internacional de Ingeniería Civily Territorio, Galicia-Norte de Portugal: Agua, cultura y Sociedad. Vigo, mayo 2013. Libro de actas ISBN: 978-84-380-0464-4.

Menor Toribio, J. (2000):La Vega de Granada: transformaciones agrarias recientes en un espacio periurbano, Granada, Universidad.

Moreno Micol, J. A. (2011): «La Huerta de Murcia. Propuestas y acciones para su conservación desde la movilización ciudadana», e-rph, $\mathrm{n}^{\circ}$ 9, pp. 1-5. 
Molina López, E. y Jiménez Mata, C. (2001): «La propiedad de la tierra en la Vega de Granada a finales del siglo XV. El caso de Alitaje», Anaquel de estudios árabes, $\mathrm{n}^{\circ} 12$, págs. 449-480.

Ostrom, E. (1990):Governing the Commons: The Evolution of Institutions for Collective Action. Cambridge, UniversityPress.

Ocaña Ocaña, M.C. (1974):La Vega de Granada. Estudio geográfico. Granada, Instituto de Geografía Aplicada del Patronato "Alonso de Herrera" (C.S.I.C), Caja de Ahorros de Granada.

Ocaña Ocaña, M.C. (1971): «Organización de los regadíos en la Vega de Granada», Cuadernos Geográficos de la Universidad de Granada, nº 1, págs. 59-83.

Ruiz Ruiz, J. F. (2013): «Sistema de riego en la Vega de Granada: el mantenimiento de un paisaje agrario a partir de los repartos de agua de riego», e-rph, Revista electrónica de Patrimonio Histórico, $\quad \mathrm{n}^{\circ} \quad 12, \quad$ pp. $1-8$. (http://www.revistadepatrimonio.es/revistas/numero12/concepto/estudios/articulo.php).

Santiago Pérez, I., Velasco García, L. y Amaya Corchuelo, S.(2007): «La protección del patrimonio cultural: ordenación del territorio y gestión del patrimonio en la Alpujarra media granadina», e-rph, $\mathrm{n}^{\circ}$ 1, pp. $1-4$. (http://revistadepatrimonio.es/revistas/numero1/concepto/experiencias/articulo.php).

Silva Pérez, R. (2008): «Hacia una valoración patrimonial de la agricultura», Scripta Nova. Revista Electrónica de Geografía y Ciencias Sociales, vol.XII, $\mathrm{n}^{\mathrm{o}}$ 275, (htpp://www.ub.es/geocrit/sn/sn-275.htm).

Silva Pérez, R. (2012): «Claves para la recuperación de los regadíos tradicionales. Nuevos contextos y funciones territoriales para viejas agriculturas», Scripta Nova. Revista Electrónica de Geografia y Ciencias Sociales, vol. XVI, no 412, (http://www.ub.es/geocrit/sn/sn-412.htm).

Trillo San José, C. (2003):Agua y paisaje en Granada: una herencia de Al-Andalus. Granada, Diputación Provincial de Granada.

Trillo San José, C. (2004): Agua, tierra y hombres en Al-Ándalus. La dimensión agrícola del mundo nazari, Granada, Grupo de Investigación "Toponimia, Historia y Arqueología del Reino de Granada.

Verdugo, J. (2005): «El territorio como fundamento de una nueva retórica de los bienes culturales», PH Boletín del Instituto Andaluz del Patrimonio Histórico, no 53, pp. 94-105. 